\title{
Why sports docudrama?: A critical review of the study of docudrama and suggestions for a historical/cultural study of Korean sports docudrama
}

\author{
Jae Chul Seo ${ }^{1}$ \& Bang-Chool Kim ${ }^{2}$ * \\ ${ }^{1}$ Seoul National University \& ${ }^{2}$ Seoul National University of Education
}

\begin{abstract}
[Purpose] The purpose of this study is to identify why and how sports docudrama is one of the unique objects for the scholarship of sport history. [Methods] As a review study, this paper pays attention to, collects, and critically reviews three dimensions of the literatures: 1) ones that claim and argue for a-historicity of historical sport films by pointing out how they are full of actual errors, mistakes, and misrepresentation, and why they are problematic, 2) ones that belong to so called 'the study of docudrama' with specific focus on the themes of definition, mode of representation, and cultural memory, and 3) ones that attempt to envision the possibility of visual history or filmic history from the perspective of historiography and some other epistemological issues. [Results] Following the above review method, the result of this paper is also divided into three parts: 1) how sport historians respond to and criticize historical sport films from the sense based on the modern historiography, 2) how a group of historians argue why historical sport films can be one of the promising way of doing histories, 3) review of the study of docudrama, focusing on what is docudrama, why it can be a mode of representation, and how it resonates to cultural memory. [Conclusions] As a conclusion, this paper argues that a more collectively academic concerns to sport docudrama paves way for developing and envisioning the scholarship of sport history.
\end{abstract}

Key words: Docudrama, Mode of representation, Cultural memory, Symbolic truth, Sport film

\section{서 론}

이 연구는 '다큐드라마(docudrama)'라는 특정한 형식 의 영상물이 등장하여 확산되고 있는 문화적 현상에 주 목하고, 이 새로운 장르를 매개로 과거에 실존했던 스포 츠 관련 인물, 사건, 이야기 등을 '기억'하고 '역사화'하는 대중(문화)적 '역사물'들에 대한 학술적 탐구가 스포츠역 사학의 비전과 가치를 확장시키는데 '특별한' 기여를 할 수 있음을 주장하고 제언하는 조그만 작업이다.

이러한 문제의식은 최근 역사학계에서 '새로운' 역사하

논문 투고일 : 2019. 02. 28.

논문 수정일 : 2019. 05. 09.

게재 확정일 : 2019. 06. 01.

* 교신저자 : 김방출 $(\mathrm{kim} 507 @$ snue.ac.kr). 기(doing a history)의 실제로 등장하여 주목 받고 있는 '대중/공공역사학(public/popular history)'에 대한 필자들 의 관심과 공감 속에서 싹튼 것이다. 역사학계에서 '대중' 의 존재가 중요하게 부각되고 있는 이유는, 그들이 단순 히 역사적 지식을 수용하고 소비하는 고객으로서의 수동 적 주체를 넘어, 그들 스스로 과거를 '소유 (ownership of the past)'하고 특정한 방식으로 재현하는 '역사하기'의 주 체로 등장하고 있기 때문이다(Andrea, 1991; Jordanova, 2000; Seo \& Kim, 2015).

'대중'에 대한 역사학적 관심은 북미와 서유럽의 스포 츠역사학 공동체에도 유입, 확산되었는데, 그 흐름은 대 략 두 가지 양상으로 표출되었다. 하나는 스포츠와 관련 된 '물질적인 것(the material)을 매개로하여 과거의 스 포츠를 '기억'하고 '역사화'하는 양상과 방식을 탐구하는 
대중적 '스포츠역사하기(doing a sport history)'의 실제 들이 우후죽순 등장하였다는 점이며, 다른 하나는, '시각 적인 것(the visual')을 매개로 하는 역사물, 예컨대 스포 츠 관련 이미지, 영상, 회화, 포스터, 만화 등을 매개로 대 중/공공역사학적 주제와 이슈를 탐구하는 흐름이 형성되 었다는 점이다. ${ }^{1)}$

이 연구는 후자의 흐름, 즉 과거에 대한 시각적 이미지 가 생산되고 소비되는 대중적 방식의 출현 그리고 그러한 '역사하기'의 변화를 추동하는 대중적이고 민주적인 역동 성에 주목한다.2) 그 중에서도 특히, '다큐드라마(docudrama)'라는 장르에 초점을 두는데, '다큐멘터리'와 '드라 마'의 형식과 성격이 혼합되어 있는 이 새로운 유형(스타 일)의 장르야말로, 과거를 '시각적으로' 전달, 표현, 재현 하거나 혹은 과거와 '시각적으로' 관계, 소통하는 '시각적 역사하기 (doing visual history)'의 대표적 형식으로 자 리 잡은 대중적 역사물이기 때문이다.

'Based on true story', 즉 실화를 바탕으로 극화한 다 큐드라마의 장르가 대중화되고 보편화된 양상의 모습들 중에는, 과거를 살아간 스포츠 인물들과 사건 그리고 그 들의 이야기들도 자리하고 있다. 대표적인 작품들을 꼽자 면, 'Black Sox Scandal'로 회자되는 1918년 메이저리그 시카고 화이트삭스팀의 승부조작 사건을 다룬 《Field of Dream》 (1988), 제 2차 세계 대전 기간 동안 창립되어 활동했던 미국 여자프로야구단과 여자야구선수들의 실화

1) 대중/공공역사학이 '시각적인 것'과 조응하게 된 배경으로, 20 세기 중·후반 인문학과 사회과학 분야에서 일어난 '시각적 전환 (visual turn)'이라는 이름의 지적 운동을 언급하는 것이 좋을 것 같다. '시각적 전환'이라는 패러다임적 표어는 '시각문화(visual culture)'의 출현, 즉 우리의 문화적 모습과 양태 및 전반적 양 식이 시각적으로 구조화되며 변화하고 있음을 함의한다. 시각적 감각을 기반으로 하는 시각성(visuality)의 편재성, 대상을 바라 보고 응시하는 시각행위 (acts of seeing)를 둘러싼 관계적 역 동성 및 정치성, 시각 기제(visual apparatus)에 작동하는 상징 과 의미 생산의 방식, 그리고 시각 매개체(visual medium)의 폭발적 증가와 그 영향력 등을 포괄적으로 아우르는 개념인 이 '시각문화'의 현상과 이슈는 오늘의 현대 문화가 과거의 전통 혹 은 근대 문화와 구별되고 차별되는 가장 큰 차이점이자 특징이다. 특히, 시각적 이미지가 생산되고 소비되는 대중적 방식의 출현 그리고 그 변화를 추동하는 일종의 민주적 역동성에 주목할 필 요가 있는데(Jay, 2002; Mirzoeff, 1999; Mitchell, 2002), 이것이 바로 대중/공공역사학이 '시각적 전환'이라는 지적 운동과 '시각문화'라는 새로운 현상의 출현과 만나는 중요한 접점이다.

2) 전자와 관련해서, 필자들은 대중/공공역사학의 문제의식과 이 론 및 인식론적 관점을 요약, 논의하고, 아울러 그러한 학술적 정향을 스포츠와 연관지어 탐구한 일련의 작업들을 '스포츠박물 관 중심으로 분류, 정리하여 소개한 바 있다. 보다 더 자세한 사 항은 $\mathrm{Seo} \& \mathrm{Kim}(2015)$ 의 연구를 참조하기 바란다
를 영화화한 《A League of Their Own》 (1992), 그리고 최근에 들어서는 메이저리그 최초의 흑인선수였던 Jackie Robinson과 1936년 베를린 올림픽의 육상 영웅 Jessie Owens의 일대기를 다룬 전기적 영화 《42》(2013)와 《Race》(2016)를 들 수 있다. 한국에서도 '스포츠다큐 드라마'로 포괄하여 이해할 수 있는 작품들이 있는데, 대 한민국 최초의 야구단을 다룬 《YMCA야구단》 (2002), 비운의 복서 김득구의 삶을 영화화한 《챔피언》 (2002), 최다 패전 투수의 독특한 이력을 가진 프로야구 선수 감 사용의 스토리를 담고 있는 《슈퍼스타감사용》 (2004), 2004년 아테네 올림픽 여자핸드볼 국가대표팀의 영광과 좌절을 재현한 《우리 생애 최고의 순간》 (2007), 그리 고 자전차왕 엄복동의 행적을 극화한 《엄복동》 (2019) 등이 대표적이다.

이 연구가 전달하고자 하는 주장은, 이러한 스포츠다큐 드라마들에 대한 '특정한' 접근과 방식의 학술적 탐구가 체육·스포츠역사학의 학술적 비전과 지평을 깊고 넓게 확 장시키는 '특별한' 가치와 기여를 제공할 수 있다는 것이 다. 특히, 그 '특정한' 접근과 방식의 안목은 '스포츠문화 사'라는 영역 그리고 '문화적 기억'이라는 주제와 관련된 아이디어들이다. 오래된 역사학의 전통과 관습과는 다소 거리가 먼 것으로 치부될 수 있는 이러한 방식의 '스포츠 역사하기(doing a sport history)'는 스포츠와 관련된 역 사적 지식 생산의 민주성 그리고 과거를 이해하고 해석하 는 다원성의 가치를 견인하고 추동하는 '특별한' 계기가 될 수 있다는 것이 핵심 요지다.

이하의 본론은 크게 세 부분으로 구성되어 있다. 먼저, 체육-스포츠역사학자들이 과거의 스포츠를 다루는 대중 (문화)적 영상물들에 대해 어떠한 (지배적) 시각과 입장 으로 그것들의 '비역사성'을 비판적으로 지적, 문제화하 고 있는지를 북미와 한국의 사례로 구분하여 소개한다. 다음으로, 과거를 다루는 영상물 혹은 이른바 '역사적 영 화'라고 표현할 수 있는 작품들의 역사적 가치와 의미 등 을 탐구한 학자들의 작업과 논의들을 수집, 종합하여 그 논리의 내용과 성격을 요약하여 정리한다. 이어서, '다큐 드라마라는 장르가 출현하여 부상하게 된 과정, 그리고 그것을 구심점으로 형성된 소위 '다큐드라마 연구'의 지형 을 개괄하여 소개한다. 끝으로, 한국 스포츠의 현실과 역 사/정치/사회/문화적 맥락 속에서 실천하고 탐구해볼 가 치가 있는 스포츠다큐드라마 연구의 몇 가지 방향성을 제 안하는 것으로 결론을 대신한다. 
과거와의 소통을 시도하거나 과거를 이야기하고 재현 하는 것은 이제 더 이상 역사학자들만이 할 수 있고 또 해 야 하는 특권과 의무가 아니다. 과거는 어느 누구에게나 열려 있는 마치 공공재와도 같은 것이기에, 누구나 '역사 하기(doing a history)'의 주체가 될 수 있다. 중요한 것 은, 전문역사학자들이 역사학의 독자/고객이자 역사하기 의 새로운 주체인 대중과 함께 소통함으로써 민주적이고 참여적인 '역사 만들기'의 문화를 조성해나가는데 앞장 서 는 것이다. 과거의 체육·스포츠 뿐 아니라 현재의 체육. 스포츠도 함께 연구하는 전문 체육·스포츠역사학자들이 '스포츠다큐드라마'라는 대중(문화)적 장르의 역사적 가 치와 유용성에 대해 열린 마음과 태도로 다가가는 짧은 미래를 상상해보며 본론으로 넘어간다.

\section{스포츠영화의 역사성에 대한 스포츠역사학계의 비판}

역사학의 '역사', 즉 역사학의 학문적 정체성을 성찰적 으로 논의하는 담론의 장 속에서, '시각적인 것' 혹은 '영 상'으로 매개되거나 표현되는 실제는 꽤 오래 동안 주목 을 받지 못한 것이 사실이다. 좀 거친 표현일지 모르지만, 이미지나 영상을 미디엄으로 하는 시각적 역사물들은 '문 자적인 것'의 그늘에 항상 가려져 있었다고 해도 과언이 아닐 것이다. 많은 문헌들 속에 나타나있듯이, '주류-전문 역사학자'3)로 칭할 수 있는 이 집합적 주체들은 과거를 다루고 재현하는 영상물들, 예컨대 역사적 영화(historical films)와 같은 텍스트의 학술적 가치에 대해 적어도 20세기 말까지는 회의적으로 바라보고 비판적으로 응시 해 온 것이 사실이다.4)

3) 영화의 역사적 가치와 잠재성에 주목하는 소위 친-영화적 역사 학자들의 논의들 속에서, 대학이라는 고등교육 기관에서 역사 학이라는 학문을 전공하여 연구하고 또 교육하고 있는 학술적 주체들은 주로 실증주의적 역사관을 중심으로 하는 '근대역사 학(modern historiography)'의 정체성이 역사학의 학문적 본 질로 인식하는 역사학자들로 묘사된다. 사실, 이들이 표방하고 지 향하는 근대역사학적 태도와 접근이 곧 역사학의 지배적 패러 다임을 구축하고 있다는 점에서, 그들을 '주류'역사학자들로 표 현할 수 있을 것이다. 자세한 사항은 Booth(2005)와 Kim \& $\mathrm{Seo}(2012)$ 의 연구를 참조하기 바란다.

4) 주류-전문역사학자들이 영화에 대해 제기하는 비판적 내용과 어조에 대해서는 Champion(2003: 155), De Groot(2006: 396-7), Rosenstone(1988; 1995: 55-60), Toplin(2002: 60-1), Walkowitz(1985: 53-4) 등을 참고하기 바란다.
단적으로 말해, 주류-전문 역사학자들이 제기하는 비 판적 관점과 논리의 핵심은 과거를 다루는 영상/시각 적 텍스트들이 '비역사적(a-historical)'이고 '반역사적 (un-historical)'이기 때문에 역사를 왜곡하는 심각한 문 제를 야기한다는 것이다. 이러한 주장을 뒷받침하는 근거 들로는, 재미를 유발하는 오락성, 감정을 자극하는 드라 마적 요소를 위해 취하는 증거의 조작, 과거에 대한 전 기적 (biopic) 접근에서 비롯되는 인물의 단순한 유형화, 나아가 사회구조와 시대의식 그리고 도시화 및 산업화와 같은 거시적 변동 뿐 아니라, 계층, 인종, 젠더, 민족성 등과 같은 심도 있는 개념과 주제를 다루지 못한다는 점 등이 제시되어 왔다. 이러한 비판적 '논거'들을 바탕으로, 주류-전문역사학자들은 과거를 다루는 시각/영상적 역사 물이 역사학의 역사성을 훼손하는 '가짜-역사물 (pseudohistory)'임을 주장해왔다.

이러한 '비판적' 시각과 관점은 과거의 스포츠를 시각/ 영상으로 재현하는 역사물들의 출현과 그 유의미성에 대 해 반응한 체육·스포츠역사학자들의 목소리와 태도에서 도 엿볼 수 있는데, 이하에서는 구체적으로 두 가지 사례 를 중심으로 논의하고자 한다. 첫 번째 사례는 북미스포 츠역사학계에서 이슈가 된 것으로, Ken Burns 감독의 다큐멘터리 《Baseball》 (1994)에 대해 스포츠역사학 자들이 개진한 비판적 리뷰와 논평에 관한 것이다. 이어 서 서술할 두 번째 사례는 과거에 실존했던 스포츠 인물 과 사건을 영화화한 작품들의 '팩션'(faction)을 분석한 두 편의 국내 연구를 소개하고 그것들을 통해 과거의 스 포츠를 영화화한 영상물들을 비판적으로 인식하는 한국 스포츠역사학자들의 지배적 관점을 읽어내는 것이다.

\section{북미스포츠역사학계의 사례: Ken Burns 감독의 《Baseball» (1994)}

북미와 서유럽의 체육-스포츠역사학자들이 과거의 스 포츠를 다루는 영상물에 대해 '특정한' 학술적 관심을 드 러내기 시작한 시기는 대략 1990 년 대 후반부터이다. 이 러한 흐름이 조성된 국면을 상징적으로 보여주는 하나의 사건이 있는데, 1996년 북미스포츠역사학회(NASSH)가 '시각적 전환'의 지적 운동을 수용하고 새로운 방향성을 탐 색해보자는 취지 아래 학술지 Journal of Sport History 에 '영화/미디어/박물관 리뷰' 섹션을 신설한 것이다. 그 리고 이 기획의 첫 번째 주제로 선정된 작품이 바로 Ken 
Burns 감독의 다큐멘터리 《Baseball》(1994)이다. 이 리뷰 섹션에서는, S. W. Pope가 작품을 선정한 이유와 배 경, 그리고 토론의 쟁점 등을 간략하게 소개하는 서문을 맡아 작성했고, 야구의 역사에 관심을 가지고 각자 나름 의 '전문성'을 구축해 온 세 명의 스포츠역사학자, Steven Riess, Jules Tygiel, Larry Gerlach가 각각 논평을 기 고하였다.

자세한 토론의 장을 들여다보기에 앞서, 먼저 Burns 감 독과 그가 제작한 다큐멘터리 《Baseball》에 대해 소개 부터 하는 것이 좋을 것 같다. Burns는 미국의 영화감독으 로서, 기록보관서의 각종 문서들과 사진 자료들로 구성하 는 역사적 성격의 다큐멘터리를 제작하는 감독이자 제작 자로 널리 알려진 인물이다. 대표적인 작품들로 《Civil War》(1990), 《Jazz》(2001), 《The War》(2007) 등 이 있으며, 최근에 발표한 《The Vietnam War》(2017)에 이르기까지 Burns는 미국의 역사와 문화에 대한 진보적 관점의 해석과 비판을 다큐멘터리의 영상 형식으로 담아 내는 작업들을 꾸준히 진행해오고 있다. 특히 《Brooklyn Bridge》 (1982)과 《The Statue of Liberty》 (1985)로 1982년과 1986년에 각각 Academy Award 수상작 후보 에 지명된 바 있다. 또한 1995년에는 《Baseball》(1994) 로 2010년에는 《The National Parks: America's Best Idea》 (2009)를 통해 Emmy Award 논픽션 작품상을 두 차례 수상하기도 하였다.

Burns 감독은 미국의 역사를 조명하는 다큐멘터리를 세 개의 독립된 주제로 구성하여 제작하는 것을 기획, 추 진하였는데, 《Civil War》에 이어 그리고 《Jazz》에 앞 서 선보인 작품이 바로 《Baseball》(1994)이다. 이 작 품은 PBS에서 제작, 방영된 TV 다큐멘터리로서 '이닝'의 이름들로 부여된 총 9편으로 구성되어 있으며, 총 분량이 18 시간에 이르는 대형 시리즈물이다. 각각의 '이닝'들은 시 대별로 구분되어 있으며, 시각적 재현과 인터뷰들, 그리고 기록보관서의 문서들과 사진 등이 다큐멘터리의 형식으 로 구성되어 있다. 그리고 인종, 비즈니스, 노동 관련 이슈, 그리고 야구와 사회의 관계 등이 Burns 감독이 다루고 있 는 주요 주제들이다.

1996년, Burns 감독이 《Baseball》을 통해 처음으로 Emmy Award를 수상하는 감격을 누린 바로 그 다음 해, 북미스포츠역사학회는 그 작품을 스포츠역사학자들이 토 론하는 원탁(roundtable)의 주제로 선정하였다. 앞서 언 급하였듯이, 이 섹션은 스포츠와 관련된 역사적 영상물의
유의미성을 학술적 토론의 장으로 포섭하고자 하는 '새로 운' 움직임에서 기획된 것이었다. 그러나 이 기고된 논평 들을 면밀히 들여다보면, 오히려 과거의 스포츠를 다루는 영상물들에 대한 '주류' 혹은 '기성' 체육·스포츠역사학자 들의 따가운 시선과 냉소적 태도가 진하게 흐르고 있음 을 알 수 있다. 그렇다고 해서, 4 명의 스포츠역사학자들이 Ken Burns 감독의 경력과 그의 독특한 역사화의 작업을 시종일관 부정적으로 곡해하는 것은 아니다.5) 논평의 시 작은 주로 작품에 대한 긍정적 평가로 시작하지만, 그'간 결한' 칭찬과 찬사 뒤에 따라오는 것은 냉엄하면서도 권위 에 찬 지적과 혹평들이다.

예컨대, Tygiel(1996)은 작품을 구성하는 영상과 이미 지들에 “정확성”이 없음을 지적하고, “조작과 왜곡과 같은 혼란스러운 패턴”과 “지나친 생략”으로 인해 “산업혁명”, “도시화”, 그리고 “사회계층의 역할”과 같은 거시적이며 사 회(구조)적인 주제에 대한 개념적 설명과 맥락적 해석이 부재함을 지적하였다. Riess(1996)의 지적은 꽤 광범위 한데, 추려서 나열하자면, 그림과 사진 자료들에 있어서 사실적 정보의 오류가 많이 엿보인다는 점, 작품을 구성하 는 내러티브 자체가 단선적이면서 협소하다는 점, 역사적 의미와 성격을 전달하고 표현하는데 있어 특정 사료들에 국한되어 제시되고 있다는 점, 도시 구조와 가족관계 및 계층과 같은 개념들이 심도 있게 논의되고 있지 않다는 점, 노동관계와 영웅적 선수들을 잘 다루고 있지만 정작 노동관계를 둘러싼 사회사적 쟁점들과 선수들의 일상과 같은 문화사적 측면들이 잘 드러나지 않고 있다는 점 등이 제시되었다. 이러한 문제점들을 나열하며 Riess(1996)는 Burns 감독이 야구사(史)와 관련된 최근의 학술적 문헌 들을 많이 놓치고 있다는 점을 제기한다. 끝으로, Gerlach (1996)의 논평은 한층 더 신랄한데, 그는 이 작품의 "사실 적 오류"와 “비정확성”이 150 개 이상에 달하며, “피상적이 면서 상투적인 표현들의 과장” 그리고 “진부하면서도 얕 은 표상과 상징들”로 인해 그것을 보는 시종일관 그가 지 루하고 또 피곤하였을 언급하며 혹평하였다.

이렇듯, Burns 감독의 다큐멘터리 《Baseball》의 역 사적 의미, 가치, 유용성 등을 진단하는 스포츠역사학자들 의 입장은 대중적 영상 역사물의 역사적 가치를 회의적으 로 인식하는 주류-전문 역사학자들의 비판적 관점과 별반

5) 예컨대, Tygiel(1996)은 이 작품이 야구 경기에 대한 전례 없는 구술적 및 시각적 역사를 만들어냄으로써 보다 더 많은 대중적 고 객들에게 어필했다는 점을 크게 강조하고 있다. 
다를 것이 없다. 특히, 비판의 대상이 되고 있는 작품의 장 르가 바로 다큐멘터리, 즉 다큐드라마보다 사실적 성격이 짙다고 여겨지는 텍스트임을 고려해 본다면, 대중적 영상 역사물에 대한 스포츠역사학자들의 시선은 훨씬 더 부정 적일 것임을 추론하는 것도 큰 무리는 아닐 것이다. 영상 이미지로 구성된 역사물에 대한 주류-전문 역사학자들의 비판적 시각은 북미의 체육·스포츠역사학계도 스며들어 '역사하기'의 본질과 정체성을 정의하고 비역사적인 것을 구별하고 배제하는 권위적이고 이데올로기적인 힘을 발 휘하고 있는 것이다.

그러나 Burns 감독의 작품들이 북미의 역사학자들로 부터 맹목적이고 획일적인 비판만 받은 것은 아니다.6) 이는 《Baseball》에 대한 북미 체육·스포츠역사학계 에서도 마찬가지이다. 2000년 대 들어, 《Baseball》과 같은 스포츠다큐멘터리 뿐 아니라 스포츠다큐드라마나 대중적 스포츠역사영화와 같은 영상 역사물들의 의미와 가치 등이 기존의 '지배적' 시각과는 '다른' 입장과 관점 에서 포착, 탐색, 논의되는 일련의 흐름들이 촉발되었다. 이러한 흐름을 추동하는 주체, 즉 영상 역사학의 가능성 을 공유하는 다양한 영역의 학자들 역시 Burns 감독의 《Baseball》에 주목하였다. 그러나 작품에 다가가는 그 들의 시각과 관점은 이전과는 사뭇 다른 것이었다(Booth, 2005; Nathan, 2014; Phillips, 2008; Phillips et al., 2007; Schultz, 2014). 흥미롭게도, 이 학자들은 모두 Burns 감독의 《Baseball》에 대한 4편의 논평을 담고 있는 Journal of Sport History의 '영화/미디어/박물관 리뷰' 섹션이 오히려 영상이미지와 관련된 역사물에 대 한 '주류' 스포츠역사학자들의 '불신'과 '냉소'를 드러내는 상징적 사례로 인용하여 논의하고 있다. Burns 감독의 《Baseball》을 둘러싼 논쟁과 대립 구도에 대한 소개 는 이쯤에서 마무리하고, 이하에서는 《Baseball》에 대 한 주류-전문역사학자들의 비판적 시선과 유사한 성격 을 엿볼 수 있는 하나의 국내 사례를 소개하고자 한다.

\section{한국 스포츠역사학계의 사례: 《우리 생애 최고의 순간》(2007)과 《퍼펙트게임》(2011)}

스포츠 관련 영상물을 역사적 문제의식과 역사적 연

6) Burns의 작품들을 대중/공공역사학의 관점에서 '긍정적'으로 바라보고 그 유의미성을 논의한 연구들로는 Harlan(2003)과 Thelen(1994)의 작업들을 참조하기 바란다.
구방법을 통해 탐구하는 경향은 국내에서도 특정한 흐 름과 윤곽을 띠며 나타나고 있다. 북미와 서유럽의 학술 공동체처럼, 영화나 영상물을 주제와 대상으로 하는 학 술지의 '특별호'나 '리뷰' 섹션 등이 기획되어 발간된 적 은 없지만, 한국의 체육 및 스포츠역사를 연구하는 대표 적 학술공동체인 '체육사학회'를 구성하여 활동하고 있 는 유수의 학자들이 스포츠영화를 포함한 각종 시각 이 미지 및 영상물들의 역사적 유용성을 다양한 접근과 방 식을 통해 탐구하고 있다. 예컨대, $\operatorname{Huh}(2014)$ 는 손기 정 연구의 사료로서 독일의 다큐멘터리 영화 《올림피아 (Olympia)》 (1938)를 분석, 탐구하였으며, Kim \& Kim (2014)은 한국 태권도영화의 역사, 즉 시대별로 태권도 영화들이 어떠한 내용과 성격으로 변천해왔는지를 분석 한 바 있다.

이상의 두 연구 모두 스포츠영화를 사료로 인식, 접근 하여 분석, 해석하는 역사적 연구의 틀과 성격을 띠고 있 다. 하지만, 이들의 문제의식이 다큐드라마의 핵심적 특 징이라고 할 수 있는 사실성과 허구성의 혼종적 조합 혹 은 관계에 대해 문제제기를 한다거나 또는 작품들이 제 기하는 새로운 역사적 유의미성을 탐색적으로 논의하는 성격의 작업을 진행한 것은 아니다. 방법론적 차원에서 보자면, 두 편의 연구들은 모두 '영화'라는 텍스트 그 자체 의 역사성을 논하는 특징을 보이고 있다.

최근 국내의 스포츠역사학계에는, 다큐드라마에 대한 국내 스포츠역사학자들의 '지배적' 인식과 관점을 유추 해볼 수 있는 유용한 연구들이 등장한 바 있다. 그것들은 바로, 스포츠영화의 내러티브를 구성하는 '사실적인 것'과 ‘허구적인 것'의 경계를 둘러싼 역사적 쟁점을 '팩션'이라 는 키워드를 통해 분석한 두 편의 연구이다. 하나는 2004 년 아테네 올림픽 여자 국가대표 핸드볼팀의 이야기를 영 화화한 작품 《우리 생애 최고의 순간》(2007)(이하 《 우. 생.순.》)의 내러티브를 구성하는 '팩션'을 분석한 $\mathrm{Ha}$ \& Chung(2010)의 연구이며, 다른 하나는 두 명의 프로 야구 선수 선동렬과 최동원의 맞대결 그리고 그들의 라이 벌 관계를 다룬 영화 《퍼펙트게임》(2011)의 '팩션'을 분석한 $\mathrm{Kim} \& \mathrm{Ha}(2015)$ 의 작업이다.

이하에서는, 두 편의 '팩션' 연구들이 천착하고 있는 문 제의식이 무엇인지를 뽑아내고, 이어서 그러한 취지 아 래 연구자들이 어떠한 구체적 작업을 진행하였는지를 요 약하여 제시한다. 끝으로, 두 편의 연구들 속에서 연구자 들이 그들의 작업, 즉 팩션 분석에 어떠한 역사적 유의 
미성을 부여하고 있는지에 대해 논의한다.

먼저, 두 편의 '팩션' 분석을 진행한 스포츠역사학자들 이 스포츠다큐드라마를 어떠한 관점으로 바라보고 문제 화하는지를 들여다보자. Ha \& Chung(2010)은 《우.생. 순》의 '팩션'을 분석하는 목적과 필요성에 대해 다음과 같이 서술하고 있다.

여자핸드볼은 $\cdots$ (중략) $\cdots$ 영화로 인해 더욱 대중의 관심이 집 중되는 '우생순 특수'를 누리게 되었다. 그러나 이러한 '특수' 가 긍정적인 것만은 아니었다. 영화를 본 관객들이 영화와

현실 차이를 무시하는 부작용이 나타나기도 하였다. 우생순 은 실화를 근거로 영화를 제작하였기에 대다수의 관객들은 어디까지가 사실(non-fiction)이며 만들어낸 스토리(fiction) 는 무엇인가를 구분할 수 없었다. 실상 대중은 영상화된 내 용을 맹목적으로 받아들이는 의식구조를 가지고 있기에 자 칫 영화 내용 모두를 그대로 사실로 받아들일 수 있는 것이 다. 영화는 그 자체가 상업적 목적을 갖고 만들어진 픽션이 기 때문에 역사의 왜곡이라고는 할 수 없지만, 영화에서의 진실성에 대한 논란은 실재 인물에 대한 오해와 실제 사건의 왜곡이라는 결과를 초래할 수도 있다. 그러기에 영화의 내용 을 체계적인 방법으로 밝히는 것은 대중을 위해 중요한 과정 이다(Ha \& Chung, 2010).

이상의 인용문은 다시 다음의 세 가지 포인트로 재 요약 하여 이해해볼 수 있다. 첫째, 영화는 실화를 바탕으로 제 작되었지만, 영화 속에는 허구도 있어서 관객들이 그것 을 인지하지 못하는 “부작용"이 일어나고 있다는 점, 둘 째, 관객들은 무엇이 사실이고 허구인지를 가려낼 수 없 기 때문에 실제 사건이 왜곡되는 결과를 초래한다는 점, 셋째, 이러한 문제점과 사태를 해결하기 위해 스포츠역 사학자들은 대중들을 위해 영화의 '팩션', 즉 사실과 허구 를 체계적으로 분석하여 밝혀내는 작업을 해야 할 필요가 있다는 것이다. ${ }^{7)}$

이러한 문제의식 아래, 두 편의 '팩션' 연구들은 영화 속 배역들과 관련된 실제 인물들과의 인터뷰를 통해 무엇 이 사실이었고 또 무엇이 허구로 삽입된 것인지를 분석한 다. 먼저, Ha \& Chung(2010)은 임오경 선수와 정형균 감독을 포함한 당시 핸드볼팀 관련자들과의 구술을 통해 영화 속 5 개의 “플롯"이 사실에 기반을 둔 것이 아니라는 점을 도출하여 제시하고 있다. 나열하자면, 첫째, 당시 국

7) $\mathrm{Kim} \& \mathrm{Ha}$ (2015)의 연구도 비슷한 목적을 제시하고 있다. 예 컨대, 그들은 제작진이 《퍼펙트게임》을 "영화로 옮기는 과정에 서 극적 긴장감을 위해 단절 또는 왜곡된 부분을 찾아 대중들에 게 객관적인 잣대를 마련할 것”임을 밝히고 있다.
가대표팀 구성원들 중에는 대형 마트에서 일한 경험을 가 진 선수가 한 명도 없었다는 점, 둘째, 국가대표팀이 구성 된 실제 과정 또한 영화 속 이야기와 크게 다르다는 점, 셋째, 영화에서 볼 수 있는 선수들 간의 갈등이 실제로는 없었다는 점, 넷째, 영화 속 훈련 보다 실제의 훈련이 훨 씬 더 혹독했다는 점, 끝으로, 영화 속 마지막 장면의 내 용이 실제의 과거와는 다르다는 것이다.

비슷한 방식으로, 《퍼펙트게임》의 '팩션'을 분석한 $\mathrm{Kim} \& \mathrm{Ha}$ (2015)의 연구는 사실과 다른 네 가지의 플 롯을 제시한다. 첫째, 영화에 등장하는 몇몇 인물, 가령 해태의 후보 포수 박만수(마동석 역)과 기자 김서형(최 정원 역)이 실제로 존재한 적 없는 가공인물이라는 점, 둘째, 실제 존재한 인물, 예를 들어 롯데의 1 루수 김용철 (조진웅 역)의 설정에 있어 실제와는 다른 내용들(출신 고교의 오류, 성격 모사에 대한 왜곡 등)이 가미되어 있다 는 점, 셋째, 영화는 두 팀의 긴장과 대결을 집단 몸싸움 으로 묘사하고 있지만, 실제 두 팀 간의 대결에서는 큰 마 찰이 없었다는 점, 넷째, 영화 속에서 볼 수 있는 최동원 선수의 '본드 투혼'은 실제 있었던 사실이 아니라 꾸며낸 설정이라는 점이 핵심내용들이다.

이러한 내용들을 통해 연구자들은 그들이 진행한 팩션 분석이 역사적으로 왜 의미 있고 가치 있는 작업인지에 대해 서술하고 있다. 먼저, Ha \& Chung(2010)은 그들 의 결론에서 다음과 같이 역설하였다.

본 연구의 팩션 분석에서 보았듯이, 영화 대부분의 내용은 실 제와 달랐다. 즉 이러한 스포츠영화의 역사화에서 지나칠 수 없는 단점은 바로 ‘왜곡’이다. 상업영화는 흥미위주의 시나리오 로 영화를 만든다. …중랙)... 영화제작사는 사실을 근거로 했 더라도 영화 전반적인 내용이 실화라고 하지 않았기 때문에 문 제될 것은 없다. 그렇다면 인증되지 않은 내용을 사실처럼 받 아들이는 대중 또는 그러한 잘못된 인식으로 생길 수 있는 실 재 인물에 대한 왜곡은 심각한 문제가 될 수밖에 없다. 이러한 이유로 본 연구에서 시도한 팩션분석은 다양한 대중역사가 범람하는 현실에서 반드시 필요한 역사화의 과정일 것이다.

$\operatorname{Kim} \& \mathrm{Ha}(2015)$ 도 비슷한 포인트를 주장하고 있다. 그들은 오늘의 시대가 어떠한 장면도 영상화할 수 있을 뿐 아니라, “팩트와 픽션의 경계가 허물어진 팩션 시대”이 며 또한 "현실보다 가상현실이 진짜로 인식되는 시뮬라르 크 시대”임을 강조하면서, “객관적인 잣대”를 가지고 사실 과 허구를 판별해내는 팩션 분석의 역사연구가 “역사"를 바로 세우고 또 "영화의 역사화”를 가능하게 하는데 기여 
함을 주장한다.

이상과 같이 살펴본 두 편의 '팩션' 연구들은 스포츠다 큐드라마의 대중적 장르가 역사의 '왜곡'이라는 문제를 초 래할 수 있으며, 이에 사실과 허구를 분간하여 가려내는 역사학자들의 작업이 그러한 '왜곡'을 방지하고 차단하는 역할을 한다는 점에서 역사적 가치와 의의가 있음을 공 유하고 있다. Burns 감독의 《Baseball》에 대해 4명의 북미스포츠역사학자들이 주로 영화라는 미디엄 그 자체 가 가지는 역사성의 한계와 문제 등에 초점을 맞추고 비 판과 지적을 제기했듯이, 국내에서 발표된 두 편의 팩션 연구들 역시 영화 속 내용의 사실과 허구를 진단하고 가 려내어 안내하는 데 초점을 두고 있는 것이다.

이쯤에서, 국내에서 진행된 이 두 편의 팩션 연구들에 대한 필자들의 견해를 언급하는 것이 좋을 것 같다. 우선, 앞으로 논의할 필자들의 논지가 두 편의 팩션 연구들을 전적으로 폄하거나 무의미한 것으로 치부하는 신랄한 비 난으로 오인되지 않았으면 좋겠다. 사실과 허구의 차이를 설정하고, 무엇이 진정으로 일어난 일이고 또 무엇이 상 상에 의해 만들어진 것인지를 분간하는 것은 역사적으로 충분히 아니 아주 의미 있는 일이 아닐 수 없다. 다만 우 리가 한번 생각해볼 점은, 사실과 허구를 지나치게 분리 하여 서열화하는 이분법적 인식이 역사연구의 본질이라 거나 또는 모든 역사연구에 있어 수반되어야 하는 필수적 인 전제는 아니라는 점이다. 사실 중심의 이분법적 논리 가 지배적 역사인식으로 작동할 때, 우리는 그것이 덮어 버리거나 혹은 담아내지 못하는 다른 다양한 역사적 의미 와 가치들에 대해 눈 멀게 될 수도 있다.

무릇 인간이란, 과거에 '실존'할 수 없고 또 과거를 진 정으로 '인식'할 수 없는 유한한 존재이다. 이러한 인간 존 재의 유한성을 생각해볼 때, 지금 우리가 알고 있는 우리 의 '역사적 앎'은 그다지 완벽할 수 없는 아니 우리 스스로 겸손해야 하는 그런 성격의 '앎'이다. 그렇다고 해서 과거 에 대한 우리의 '앎'이 항상 불완전한 것이라고 단념하며 살아가야 한다는 의미는 아니다. 요컨대, 과거에 대한 우 리의 역사적 '앎'은 특정한 하나로 통일되고 획일화된 것 으로서의 '좋은' 것이 있고, 또 때로는 다채롭고 다원화된 것으로서의 '좋은' 것들도 있다. 바로 이 후자의 쟁점, 즉 필자들은 과거의 스포츠를 다루고 재현하는 영상물의 역 사적 가치와 유용성이 스포츠역사학자들로 하여금 과거 의 스포츠에 대한 우리의 '앎'에 대해 보다 더 다채롭고 다 양한 접근과 방식으로 성찰할 수 있도록 안내하는 데 '특
별한' 기여를 한다고 믿는다. 이에, 비록 두 편의 팩션 연 구들과는 조금 다른 성격의 작업이라 할지라도, 스포츠다 큐드라마를 탐구하는 특정한 방식의 문제의식과 접근 (historical inquiry)이 스포츠역사학의 확장을 견인하는 '충분한' 아니 큰 기여를 산파하는 가치 있는 시도임을 주 장하고자 하는 것이다.

예를 들어, Ha \& Chung(2010)은 "임순례 감독이 여 자핸드볼을 선택한 이유[가] 감동의 기억 때문”이었음을 언급하고 대중적 스포츠 영상물들이 감정과 정서에 초점 을 맞추고 있다는 점을 인정하고 있다. 그렇다면, 스포츠 영화가 만들어내는 '감동'과 그 작품이 토대로 하고 있는 실제 사건, 즉 과거의 실제 선수들이 만들어 낸 그 '감동' 은 같은 것인가, 다른 것인가? 실제 사건이 일어났던 과 거의 그 '진짜' 감동은 영화로 그대로 복사 혹은 복제해서 다시 만들어낼 수 있는 성격의 것인가? 아니, 영화가 아 니더라도 우리는 어떻게 과거를 다시 그대로 만들어낼 수 있는가? 어떤 역사가 그것을 실제로 할 수 있는가? 과거 의 그 '진짜' 감동과 다르다면, 영화가 만들어내는 그 '가 짜' 감동은 우리에게 전혀 의미가 없는 것인가? 허구적 감 동 뿐 아니라, 영화의 내러티브 속에 존재하는 다양한 비 -사실적 요소들은 역사적으로 무의미한 것들인가?

필자들의 주장은 허구도 사실과는 다른 성격과 방식으 로 역사적 의미를 제공한다는 것이다. 다시 말해, 사실과 허구의 경계를 탐구하는 팩션 연구의 역사적 가치와 유용 성은 다양한 방식과 성격으로 존재할 수 있다. 과거에 일 어났던 실제 사건의 사실성을 명확하게 정립하고, 영상물 의 허구성이 어디까지인지를 밝히는 것만이 역사학자들 이 '팩션'에 대해 접근하여 분석해야 하는 '유일한' 혹은 '최선의' 방식은 아니다. 역사학자들은 팩션이 조장하게 되는 착오와 왜곡을 비판적으로 직시하여 교정하는 역할 도 해야 하겠지만, 바로 그 팩션이 과거와 현재 그리고 미 래 사이에서 어떠한 의미와 상징관계를 생산하고 매개하 며 상호작용하는지에 대해서도 관심을 가지고 개입할 필 요와 책무가 있다. 특히, 과거의 스포츠를 영상으로 소환 하여 재현하는 대중적 영상물의 팩션에 대해서도 스포츠 역사학자들은 다양한 방식으로 접근하여 분석하고 탐구 할 필요가 있는 것이다.

이하에서는, 그러한 구체적 방식들을 제언하기 위한 안목을 도출하는 차원에서, 영화를 둘러싼 역사학적 이 론, 인식론 및 방법론적 이슈와 쟁점들의 지형 속으로 잠 시 들어가고자 한다. 특히, 영화로 역사를 하는 작업과 실 
제의 가능성을 긍정적으로 조망하고 탐색한 학자들의 논 의, 그리고 '다큐드라마'라는 특정한 장르에 초점을 두고 팩션의 역사성을 새롭게 검토한 연구들의 지형을 검토 함으로써, 스포츠다큐드라마를 통한/에 대한 스포츠역사 연구의 방향성을 제언하는 안목과 통찰을 사유해보고자 한다.

\section{영화를 통한/에 대한 '역사하기'의 가능성을 탐색하는 논의들}

'시각적 전환'이라는 지적 움직임은 역사학에서도 큰 '변화'를 몰고 왔다. 점점 많은 역사학자들이 '문자'로 된 것 뿐만 아니라 '시각적인 것' 역시 역사적 사료와 증거 로서 그리고 그들이 수행하는 역사적 탐구의 대상으로서, 더 나아가 그 자체를 일종의 '역사하기'의 산물 또는 하나 의 ‘역사화’된 역사물로 인식하는 접근과 태도가 등장한 것이다. 이러한 흐름은 대략 1990 년대 초부터 형성되기 시작하였는데, 이것을 가령 '시각적 역사학 운동 (visual history movement)'로 표현할 수 있을 것이다. ${ }^{8)}$ 이하에 서는, 과거와 관련된 주제와 이야기를 재현하고 표현하는 역사적 성격의 영화가 가지고 있고 또 그것이 매개하는 학술적 가치를 긍정적으로 탐색하고 실천한 소위 '친-영 화적 역사학자들'에 주목하고, 그들이 천착하는 문제의식, 주류-전문 역사학자들의 비판에 대응하는 논리와 근거, 나아가 그들이 제안하고 제기하는 '영화적 역사'의 성격과 방향성 등에 대한 논의들을 중심으로 서술하고자 한다.

먼저, 친-영화적 역사학자들이 영화에 대한 비판적 시 각과 목소리에 대응하는 방식부터 살펴보자. 그들은 역사 적 영화의 가치를 부정하는 태도와 관점이 주로 '문자(적) 역사(written history)'와 '영상/시각(적) 역사(visual history)'를 서로 상치되고 대립되는 이분법적 관계로 파악 하는 인식론적 관행에서 비롯되는 것임을 지적한다. 예컨 대, 둘 사이의 이분법적 관계는 '복잡성 대 단순성', '사회 적(구조적) 대 개인적(인물 중심)', '사실적 대 허구적',

8) 이러한 흐름의 시발점을 촉구한 하나의 중요한 국면이 있다면, 그것은 1988년 저널 The American Historical Review가 '이미지 속의 역사, 역사 속의 이미지'라는 제목으로 특별호를 간행한 시점이다. 여기에는, Robert Rosenstone, Hayden White, Robert Toplin, John O'Conor 같은 역사학자들이 논평과 에세이들을 기고하였는데, 이후, 많은 후속 세대 학자들 이 이 특별호의 간행을 중요한 전환점으로 자주 언급하고 있다.
'교육적 대 오락적' 등과 같은 요소들로 구축된다. 이항대 립이 '특정한' 위계와 서열의 관계를 구성하고 형성하는 경우가 많듯이, 역사학의 본질과 정체성을 정의하고 논의 하는 담론 내에서도, '문자(적) 역사'는 '우등한 것', 즉 일 종의 '이상적'이며 '전문적'인 역사로 구획된다. 반면, '영 상/시각적 역사'는 '대중적'이거나 '오락적'인 특징도 있지 만, 이항대립적 관계에 의해 이상적이지 않고 전문적이지 않은 소위 '열등한 것’으로 환원된다(Champion, 2003; De Groot, 2006; Rosenstone, 1988; Toplin, 2002; Walkowitz, 1985; Wildt \& Selwyn, 1996).

친-영화적 역사학자들이 보기에, 이러한 이분법적 접근 은 '영상/시각적 역사'를 '문자(적) 역사'의 입장에서 비교 하고 대조하는 것에 지나지 않기 때문에 아무런 의미가 없 다. 엄밀하게 말한다면, '문자(적) 역사'도 '완전한' 역사 가 아니며, '영상/시각(적) 역사'가 가지고 있는 한계나 문 제점들, 예컨대, 증거를 배열하고 결합하는 조작성 (manipulative elements), 인과관계의 여백을 상상으로 채우는 허구적 본질 (fictive nature) 등으로부터 결코 자유로울 수 없다는 것이다(Toplin, 2002; White, 1988).9) 그들 이 주장하는 것은, 오히려 '문자'가 '갑'으로 '영상/시각'이 '을'로 존재하는 이 이분법적 인식이야말로 주류-전문역 사학자들이 역사학 내의 헤게모니적 권위를 잡고 있는 권 력 관계 속에서 만들어지고 구축된 하나의 산물이라는 것 이다. 다시 말해, '영상/시각적 역사'의 가능성과 가치를 폄하하고 그 학술적 한계에 대한 목소리를 끊임없이 높 이는 것은, '영상/시각적 역사' 그 자체에 대한 '실제적'이 고 '객관적'인 비판이라기보다는, 역사학 내에서 '문자 역 사'가 점하고 있는 권위와 지위를 재차 확인하고 다시 강 화하는 성격의 역할이 더 크다는 점이다(Burke, 2002; Harlan, 2007).

이러한 비판의 자가당착성과 정치성에 대한 지적이 친 -영화적 역사학자들이 제기하는 궁극적인 주장의 핵심은 아니다. 그들이 호소하는 것은 '영상/시각적 역사'의 등장 과 출현을 발판과 계기로 삼아 역사학의 본질과 정체성을

9) 예컨대, Toplin(2002)은 다음과 같이 주장한 바 있다: "영화감 독뿐 아니라 역사가와 역사교사 역시 역사적 증거를 조합하고 배열하는(manipulate) 주체임을 강조한 바 있다. 단, 역사학자 들은 역사에 대해 말하고 쓰는 어떤 정도의 해석과 관련된 일종 의 면허증을 가지고 있는 셈이다. 역사학자들 역시 특정한 사건 과 사실을 그들의 시각과 입장에서 선택하여 해석하고 또 주장 한다는 점에서 순수하게 객관적이며 비정치적(partisan way) 일 수도 없다(p. 2). 
성찰하고, 나아가 역사학의 확장과 책무를 고민하는 '열 린' 관점과 태도이다. 다시 말해, 친-영화적 역사학자들이 제안하는 '영상/시각적 역사'에 대한 '열린' 관점과 태도 라는 것은 과거에 대한 서로 다른 '역사하기'의 가능성을 인정하는 것이다. '문자(적) 역사'와 '영상/시각적 역사'를 비교와 대조의 이원론적 시각으로 갈라놓고 분리하기 보 다는, 둘 다 과거를 재현하고 또한 '역사하기'를 매개하고 가능하게 하는 일종의 '다른' 형식으로 이해하고 그 차이 를 인정하자는 것이다.

Robert Rosenstone (1992)이 지적하였듯이, 많은 (주 류-전문)역사학자들은 과거를 다루는 영상물을 문자로 쓰인 역사의 시각적 변환으로 흔히 인식하고, '문자 역사' 가 영상으로 잘 '번역'되는지에 몰두하는 경향이 있다. 그 리고 이러한 '번역'의 관점과 태도는 '영상/시각적 역사' 의 가치와 가능성에 대한 ‘닫힌’ 믿음과 판단으로 이어진 다. 가령, 영화적 재현은 역사적 지식과 정보를 전달하기 힘들다는 믿음, 그래서 과거를 영상을 매개로 재현하는 역사적 작업은 불가능한 것이라는 판단, 그렇기에 (역사 적)영화감독들은 역사학자가 될 수도 없고 또한 그래서 도 안 된다는 결론으로 이어진다는 것이다.

그러나 친-영화적 역사학자들은 글과 문자로 작성되고 엮어진 책으로서의 역사가 이미지와 영상으로 배열되고 편집된 영화로서의 역사보다 훨씬 더 우월한 것임을 잘 알고 있다. 또한, 영화의 내러티브 속에 흐르고 있는 일 련의 허구적 요소들, 그리고 그것들에 스며있는 속임수 (tricks)가 불러오는 효과와 파장들, 더 나아가 그 허구적 요소와 속임수에 묻혀 버릴 수 있고 사장될 수 있는 '역 사성 (historicity)'들을 인지하지 못하거나 간과하는 것 도 아니다(Toplin, 2002; De Groot, 2006).

요지는, 역사하기의 '옳고' '그름', 그리고 '좋고' ‘나쁨'의 본질을 따지는 것에 초점을 두기 보다는, 서로 다른 '역사 하기'의 존재 가능성을 믿고 그 차이를 인정하는 가치와 태도가 이제 필요하고 또 중요하다는 것이다. 역사학자 들이야말로 과거와 현재의 존재론적 간극을 직시하고, 과 거를 이해하고 안다는 것의 인식론적 한계를 견지해야 하 는 겸손의 미덕을 갖추고 있는 사람들이다. 과거를 재현 하는 매개적 수단, 그리고 역사학자들이 그들의 주장을 표현하는 형식 역시 그러한 존재론적 간극과 인식론적 한 계를 결코 뛰어넘을 수 없다.

역사학의 역사·철학적 본질과 근원적 한계 등을 성찰 하는 문제의식과 태도 아래, 친-영화적 역사학자들은
'(전문적)역사하기' 역시 미래의 시대적 변화에 부응할 수 있어야함을 강조한다. 그들에게 있어 '역사하기'라는 하 나의 실제는 특정한 형식과 내용으로 존재하는 고정 불변 의 그 '무엇'이 아니다. 인류가 존재해 온 역사 속에서 시 대적 변화에 맞춰 그 형식과 내용이 구성되고 변화하면 서 또 진화되어 온 하나의 사회·문화적 산물이다(Burke, 2002; Champion, 2003; Harlan, 2007). 인류가 과거를 이야기로 구전하여 전승하던 시대를 넘어 '역사'라는 실 제를 가지게 된 것은 문자 혁명에 기인한 것이었다. 그 이 후로도 '문자(적) 역사'는 문자적 형식의 역사적 진화를 거듭해왔는데, 가령 주석을 붙이고 인용을 삽입하는 역사 (학)적 기술(historical craft)은 사건을 목격하고 증언하 는 문화가 만들어지면서 새롭게 발명된 것이다(Grafton, 1997; Champion, 2003).

이렇듯, 역사(학)적 기술의 '역사성'을 고려해 볼 때, 영상과 시각으로 표현, 생산, 매개되는 문화적 일상성은 오늘의 역사학자들이 인간 문명과 사회·문화를 이해하는 시대적 조건과 환경으로 간과해서는 안 될 하나의 중요한 범주(literacy)이다. Rosenstone(1988)이 역설하였듯이, 오늘을 사는 그리고 내일을 살아갈 우리 인간이 이미지가 없는 세계에서 산다면 아무런 문제가 되지 않을 것이다. 이미 현대의 대중들은 문자보다는 영상과 이미지에 더 친 숙해져 가고 있고, 또 그것들을 통해 과거를 이해하고 소 통함은 물론 과거에 대한 영감과 아이디어를 얻고 있다. David Harlan(2007)이 피력하듯이, 이제 역사학자들은 미래 세대에 출현할 '차세대 역사하기(future historiography)'의 형식과 내용 그리고 성격 등에 대해서도 관심 을 가지고 고민해볼 필요가 있다. 비록 그것을 아직 명확 하게 '정의'하기는 힘들겠지만, '미래의 역사하기(future historiography)'를 특징짓는 다양한 요소들로 '시각적인 것'은 단연코 포함될 것이다.

국내에서도, 과거에 대한 주제와 이야기를 영상으로 표현하고 재현하는 '역사하기'의 가능성을 긍정적으로 조 망하고 탐색, 논의한 작업들이 있다. 예컨대, '영상역사학 (visual history)'의 개념을 소개하고 그 유의미성을 역 설한 $\operatorname{Kim}(2008)$ 은 다음과 같이 주장한 바 있다.

전통적인 역사학이 문자기록에 근거하고 문자로 구현되는 역 사물을 주된 연구 및 활용대상으로 했다면, 영상역사학은 새 롭게 '영상기록'과 '영상으로 구현되는 역사물'의 분석.연구.창 출·활용을 탐구하는 역사학이라고 정의할 수 있다. $\cdots$ (중략) 
영상이 이야기를 갖고자 할 때, 어떠한 분야보다 역사를 찾 는다. 상상력도 사실을 기초로 발아하는 것이므로 과거의 역 사는 항상 중요한 영상의 소재가 된다. $\cdots$ (중략)

이러한 점에 착안하여 필자는 앞으로 역사학은 다양한 방식 으로 영상과 만날 것이며, 그에 따라 영상과 역사의 결합과 관련된 제반 사항을 탐구하는 영역을 '영상역사학'이라고 명 명하고, 앞으로 역사학은 새로운 역사학의 확장으로서 그리 고 다른 일면에서는 새로운 역사학의 책무로서 영상역사학 에 관심을 가질 것을 제시한 것이다.

$\operatorname{Kim}(2008)$ 이 분류하고 있듯이, 시각 이미지와 영상 은 두 가지 범주로 역사적 유의미성을 발산하고 있다. 하 나는, 영상으로 기록된 사료로서의 가치이며, 다른 하나 는 영상으로 구현되고 표현된 역사물로서의 가치인 것이 다. 이러한 '영상역사(학)'은 기존의 전문 역사(학)과 대 치되고 반대되는 개념과 실제가 아니다. 문자로 기록되고 구현되는 것 그리고 영상으로 기록되고 구현되는 것의 조 화를 통해 과거에 대해 보다 더 풍부하고 폭 깊은 이해를 추구해 나가는 것은, 미래 세대의 역사학자들이 역사학의 확장이라는 비전을 실현하기 위해 실천해야 하는 새로운 책무인 것이다.

지금까지, 과거를 다루고 이야기하며 재현하는 (역사 적)영화들에 대한 주류-전문역사학자들의 비판은 무엇 인지, 그리고 그 비판에 대해 친-영화적 역사학자들이 어 떻게 대응해왔으며, 나아가 '영화(적) 역사' 혹은 '영상/시 각적 역사'의 가치와 중요성을 역사학의 확장과 역사학자 의 책무라는 새로운 비전과 사명의 일환이자 촉매로 바라 보는 인식 등을 서술하였다. 다음 장에서는, 영화를 통한 혹은 영화에 대한 '역사하기'의 가능성과 유의미성을 탐색 하고 실천하는 접근과 담론들의 핵심으로 부상하여 주목 받고 있는 다큐드라마 관련 연구의 지형으로 폭을 좁혀 한 걸음 더 들어가 보고자 한다.

\section{'다큐드라마 연구'의 지형과 담론}

'Based on True Story', 즉 실존했던 인물과 실제 일어 났던 사건을 한 편의 이야기로 구성하여 표현하는 (대중) 문화적 실제가 등장, 확산, 대중화되는 과정과 흐름 속에 는 몇 가지 중요한 국면 혹은 계기가 자리하고 있다. 먼 저, TV가 존재하지 않던 시절, '대중'과 '역사'를 매개하고
관계하는 중요한 역할의 축을 담담했던 할리우드의 초창 기 서사 영화들 (epic)이 있다. '영화'라는 새로운 종합예 술이 스튜디오 시스템을 통해 고도의 '성장'을 맞이하던 시 기에, 과거를 살아간 특정 인물의 일생을 '전기'의 형식으 로 '이야기'하는 스타일 (bio-pics)이 등장한 것이다. 학교 이외에는 특별히 '역사'를 가르치고 매개하는 제도적 실제 가 없던 그 시절, 관객과 대중들은 스크린 속 위대한 인물 들의 일생을 이야기로 감상하고, 소통하면서 공적 (전문 적) 역사와는 또 다른 '역사적' 의식을 형성할 수 있었다 (Fraser, 1999; Custen, 1999; Rosenthal, 1999).

할리우드에서 시작된 이 대중적 영상 역사물의 형식은 2차 대전 이후 TV의 대중적 보급과 함께 특정한 '장르'의 형태를 띠며 확산되었다. 영국의 경우 1960년대 초부터 그리고 미국에서는 1970년대 초부터, 과거를 영상물의 형 식을 통해 이야기하는 문화가 더욱 더 대중 속으로 파고 들어가기 시작하였다. 한 가지 특이한 점은, 당시 제작된 영국과 미국의 영상물들이 그 내용과 성격에 있어 매우 대조적이었다는 것이다. 예컨대, 영국식 스타일이 정치 적이고 사회적인 이슈와 문제 등을 진지한 방식으로 다 룬다는 점에서 저널리즘이나 뉴스의 성격이 짙었다면, 미 국식 스타일은 다소 오락적이고 자극적인 스캔들 중심 의 소재를 통해 청취자들이 방영 시간의 대부분을 즐길 수 있도록 구성하였다는 점에서 예능 프로그램으로서의 성격이 강했다(Corner, 1999; Hoffer \& Nelson, 1978; Rosenthal, 1999).

$\mathrm{TV}$ 를 통해 큰 열 풍을 몰고 온 이 대중적 영상 역사물 의 등장은 1990 년대 들어 할리우드의 스크린을 통해 다 시금 폭발적으로 점화되는 계기를 맞이하였다. 예컨대, 《J.F.K.》 (1991), 《아버지의 이름으로(In The Name Of The Father)》 (1993), 《쉰들러리스트(Schindler's List》 (1993) 같이 과거의 인물과 사건을 다룬 작품들이 연이 어 대대적인 흥행을 기록하였고, 그 과정 속에서 각각의 작품들이 다루는 '과거(들)'과 현재의 관계를 둘러싼 다 양한 이슈와 쟁점들이 촉발되고 양산되는 '신드롬' 현상 이 일어났다. 앞 장에서 주류역사학자들과 친-영화적 역 사학자들의 대립 구도를 언급하였듯이, 이 영화들에 집중 된 세간의 이목들과 논쟁 속에는 객관적이고 실증적 차원 의 역사적 문제점을 제기하고 지적하는 날선 비판들이 자 리하고 있다. 그러나 '가능성'의 차원에서 이 작품들이 매 개하고 발산하는 '역사성'의 의미와 가치를 이른바 '역사 적 영화(historical films)라는 이름으로 의미 부여하는 
관점과 논의들이 더욱 증폭된 것도 사실이다.

특히, 이 국면에서 주목할 점은 다양한 이름들로 명명 되고 표현되고 정의되기 시작한 이 대중적 영상 역사물 을 보다 더 학술적으로 탐구해보고자 하는 '진지한' 관심 과 시도들이 인문학과 사회과학의 경계를 넘나들며 나타 나기 시작한 것이다. '역사'와 '영화'가 관계하는 이론적 지 형과 인식론적 양상에 관심이 많은 영화역사학자 및 영 화철학자들은 물론, 문화사 또는 포스트모던 역사학자 들, 아울러 문화연구, 영상인류학, 기억연구, 시각문화연 구 등과 같은 학제적 분야의 학자들까지 과거의 실존 인 물과 사건을 특정한 이야기의 내용과 형식으로 재현하는 이 영상물에 대해 각자의 관점과 문제의식으로 뽑아낸 다 양한 질문들을 제기하고 또 탐구하기 시작하였다.

1990년대부터 형성되기 시작한 이 학술적 담론의 지 형은 대략 몇 가지 핵심적 (혹은 지배적) 질문들로 틀 지 어 이해할 수 있다.10) 첫째, 새롭게 등장한 대중적 영상 역사물들을 어떻게 '정의'할 것인가의 문제의식이다. 구 체적으로, 오랜 기간 대중과 함께 호흡해 온 이 영상물의 집합적 존재 양식을 무슨 종류의 '장르'로 어떻게 '규정' 할 것인지, 나아가 그것은 다큐멘터리와 드라마와 각각 어떻게 관계되고 또 구별되는지, 또한 그것의 형식을 판 별하고 가려내는 경계는 무엇인지를 질문하고 탐구하는 것이다. 두 번째 질문은 이 대중적 영상 역사물의 '목적'과 '성격'과 관련된 것이다. 사실과 허구가 공존하는 이 영상 물이 전송하는 메시지들은 주로 무슨 주제들인지, 그리고 그것들은 왜 관객(시청자)들에게 매력적으로 다가가는 것인지 등을 질문하고 탐구한다. 끝으로, 이 영상물의 '의 미'와 '가치'에 관해 질문하고 논의하는 흐름이 있다. 예컨 대, 이 영상물들은 우리 사회 속에서 어떠한 유의미한 역 할과 기능을 수행하고 매개하는 문화적 주체(cultural agent)인지를 질문하고 탐구한다.

이하에서는, 이 세 가지 핵심 질문들을 축으로 유형화 할 수 있는 학술적 담론들의 지형을 간단히 요약적으로 정리하여 제시할 것이다. 아울러, 1990 년대 이후 등장한 대중적 영상 역사물의 집합적 형식들을 이 지점부터 '다

10) 과거의 실존 인물과 사건을 이야기의 형식과 내용으로 구성하 는 영상물에 대해 학자들이 던지는 질문들은 그들의 입장과 관점 그리고 지적 배경에 따라 다양할 수 있을 것이다. 필자들 은 주로 Caughie(1980), Custen(1992), Lipkin(2002, 2011), Toplin(2009), Rosenstone(1988, 1992, 1995), Paget(1990, 2002, 2004, 2007), Rosenthal(1999)의 문 헌들을 참고하였음을 밝혀둔다.
큐드라마'라는 이름의 장르 혹은 스타일로 명명하고 서술 하고자 한다.

\section{‘다큐드라마’란 무엇인가}

'다큐드라마'는 문자 그대로 '다큐드라마'와 '드라마'의 합성어이다. 그러나 이 두 단어의 합성이 정확하게 무엇 을 의미하는지에 대한 명확한 규정이나 합의는 존재하 지 않는다. 사실, '다큐드라마'라는 개념은 유수의 다른 용어들과 비슷한 방식으로 혹은 미묘한 차이를 띠며 소통 되고 있다. 학자들마다 다양한 개념들을 사용해왔는데, 'faction', 'dramadoc', 'bio-pic', 'reality-based film,' 'docufiction', 'fact-based drama', 'drama documentary' 등이 대표적인 용어들이다(Feuer, 1995; Lipkin, 2002; Rhodes \& Springer, 2006).

다큐드라마를 연구하는 대표적 학자들 중의 한 명인 Alan Rosenthal(1999)은 다큐드라마에 대한 가장 '무난 (prosaic)'하면서도 '적절한(workmanlike)' 정의의 예로, Hoffer \& Nelson(1978)의 설명을 들 수 있다고 주장한 바 있는데, 그것은 다음과 같다.

[다큐드라마는] 사실과 허구의 독특한 조합으로 우리의 기억 속에 존재하는 역사적(historical) 인물과 사건 등을 극적으로 구성(dramatize)한다. 그것은(다큐드라마는)] 지나간 과거의 사 건을 재연(recreate)학 위해 배우, 대화, 세트, 복장 등에 의존 한다는 점에서 사실에 기초한 하나의 TV 오락(여가)이다. 그 러한 여가적/오락적 활동에 내재하는 사실성과 포괄성의 범 위는 매우 광범위하며, 예산 및 상연시간 등의 여러 요인들로 다양하게 구성될 수 있다(Hoffer \& Nelson, 1978; Rosenthal, 1999).

이상의 인용문이 담고 있는 요점은 두 가지다. 하나는, 다 큐드라마가 '사실성'과 '허구성'의 조합과 양상으로 이루 어져있다는 점, 다른 하나는 그 조합을 구성하는 관계의 양상이 광범위하고 또 다양하다는 점이다.

Rhodes \& Springer (2006)에 의하면, 다큐드라마의 '사실성'과 드라마의 '허구성'이 관계하는 조합은 다시 4 가 지 양상으로 구분할 수 있는데, 그것은 다큐멘터리의 '형 식'과 '내용' 그리고 드라마의 '형식'과 '내용'이 각각 연결 될 수 있는 경우의 수를 생각해보는 것이다. 간단히 말해, '다큐멘터리'라는 것은 다큐멘터리의 '형식'과 '내용'을 가 지고 있는 것이다. '드라마' 역시 드라마의 '형식'과 '내용' 으로 구성되어 있다. 여기에서, 우리는 '다큐멘터리의 형식' 
과 ‘드라마의 내용'이 결합된 것을 상상할 수 있는데, 이는 과거에 실존하지 않은 허구적 인물과 사건을 '다큐멘터리' 적 기법과 양식을 활용하여 제작한 영상물로 이해할 수 있다.11) 반대로, '다큐멘터리의 내용'과 '드라마의 형식'이 접합된 것도 상정해볼 수 있는데, 이것은 과거에 실존한 인물과 사건을 허구적 혹은 드라마적 요소와 형식으로 이 야기화한 영상물이라 할 수 있다.

이 조합, 즉 과거에 실존했던 인물과 사건을 이야기의 틀과 구조로 담아내는 영상물들의 집합이 바로 필자들이 '다큐드라마'라는 용어로 포괄하여 지칭하고자 하는 대상 들이다. Lipkin(2002)이 표현한 바 있듯이, 다큐드라마는 "다큐멘터리의 내용적 제재와 드라마(특히 멜로드라마) 의 관습이 잘 결합되어 있는 혼종적 형식(a hybrid form)" 이다. 이 지점에서, 우리는 스포츠와 관련된 내용을 연관 지어 생각해 볼 수 있는데, 가령 과거에 실존했던 스포츠 관련 인물들과 사건들을 드라마적 형식과 관습 혹은 문법 들로 '이야기'화하여 재현하는 영상물들을 '스포츠다큐드 라마'로 이해할 수 있다.

(스포츠)다큐드라마를 정의하는데 있어 고려해야 할 핵심적 사항은 그것이 발산하는 '혼종성'의 본질 또는 성 격을 간과하지 않는 것이다. Leslie Woodhead(1981)가 피력하였듯이,

정의를 하는 것도 중요하지만, 다큐드라마를 일종의 스펙트 럼으로 인식하는 것이 보다 더 유용하다. 그리고 그 스펙트럼 은 저널리즘적 재구성에서부터 오락적이고 창조적인 허구적 드라마에 이르기까지 매우 다양하다. 그 다양한 변형들 속에 는 사건의 경위를 추적해나가는 저널리스트들도 있고, 다큐 멘터리 제작자들도 있으며, 상상으로 풍만한 작가들도 숨어 있다. 다큐드라마의 프로그램들이야말로 정말 다채롭고 다 양하게 존재할 수 있는 것이대(Woodhead, 1981; Rosenthal, 1999).

11) 1960 년대 영국에서 유행한 TV 영상물들이 대표적 사례이다. 즉 허구의 이야기가 다큐멘터리적 형식으로 구성되어 있어 저 널리즘적 경향의 색채를 띠고 있다(Caughie, 1980; Hyung, 2016). 한 가지 덧붙이자면, Rhodes \& Springer(2006)은 이러한 조합의 영상물들을 '모큐멘터리(mockumentary)'로, 그리고 Paget(2004)은 '드라마 다큐멘터리(drama documentary)'라는 용어로 개념화하면서 각각 '다큐드라마'와 구별하고 있다. 그러나 Caughie(1980)은 정작 '다큐드라마'라는 용어를 사용했기 때문에 같은 이름이지만 그 조합의 양상은 사뭇 다르 다고 할 수 있다. 이렇듯, 학자들이 조탁하여 사용하고 있는 다 양한 용어들 그리고 그러한 용법들과 관련된 일련의 쟁점과 문 제점 등에 관한 요약과 논의는 Hyung(2016)의 연구에 잘 정 리되어 있으니 참고하기 바란다.
요약컨대, 다큐드라마를 고정된 그 '무엇'으로 이해하기 보다는, '사실'과 '허구'의 다양한 조합들이 '같으면서도 다 름'의 양상을 집합적으로 구성하고 형성하는 것으로 인식 할 필요가 있다.

이러한 다양성과 차이의 존재를 인식함과 동시에, 다른 한편으로 우리는 다큐드라마들의 집합을 관통하고 아우 르는 '공통적'이고 '보편적'인 일종의 '전형성'을 생각해볼 수 있다. Toplin(2002)이 이를 잘 정리한 바 있는데, 구체 적 내용을 요약하자면 다음과 같다. 첫째, 다큐드라마는 인물과 사건에 대한 주제, 정보, 이야기 등을 약 2 시간 정 도의 내러티브에 안에 담아내기 위해 구체적이고 세부적 인 사실, 정황, 행동(행위) 등을 압축적으로 재현한다. 둘 째, 드라마의 일반적 플롯, 즉 안정적이고 균형적인 상태 에서 갈등 혹은 문제가 발생됨을 보여주고, 이어서 그 문 제와 갈등을 해결하는 내러티브의 과정을 구성한다. 셋 째, 이러한 내러티브의 구조와 과정 속에서 등장인물들은 영웅과 악당으로 명확히 구별되어 재현된다. 넷째, 사건과 이야기를 표현하고 전달하는 영화적 장치와 기법 등을 통 해 관객들로 하여금 과거에 대한 감정과 정서 (a sense of the past) 그리고 과거적인 것 (pastness of the past)에 대한 공감을 불러일으킨다.

필자들은 Topin(2002)이 정리한 4가지 전형성의 가치 와 유용성을 '형식'과 '내용'이라는 두 축으로 변환하여 다 시 사유하고자 한다. 요지는, 다큐드라마의 전형성을 구성 하는 '형식'과 '내용'을 각각 '모드(mode)'와 '기억(memory)' 이라는 키워드로 포착하여 이해할 수 있다는 것이다. 이 하에서는, 두 절로 구분하여 각각에 대해 보다 더 자세히 상술한다.

\section{과거를 재현하는 ‘모드(mode)’로서 다큐드라마}

과거를 다루거나 혹은 그것에 대해 이야기하고 표현하 며 재현하는 다른 영상 텍스트들처럼, 다큐드라마는 '특 정한(혹은 지배적 ' 관점의 역사적 비판, 냉소, 회의, 불 신 등으로부터 자유롭지 않다.12) 무엇보다, 사실과 허구 의 '독특한' 조합이라는 이 혼종성이야말로 다큐드라마 속

12) 다큐드라마는 고의에 의한 것이든 혹은 부주의에 의한 것이든 객관적 사실과 사건에 대해 청중들을 속이는 효과와 결과를 만 들고 있음을 부정할 수 없으며, 이는 결국 역사 왜곡 뿐 아니라 특정한 정치적 당파성을 선전하는 장으로 전락할 수 있다는 지 적 등이 있다. 다큐드라마에 대한 역사적 관점의 비판적 지적 은 Edgar(1999)의 연구를 참고하기 바란다. 
진실의 중심은 어디에 있는지 그리고 그것은 얼마나 믿 을만한지를 계속해서 질문하게 만드는 근원적 단초인 것 이다. 그러나 Rosenthal(1999)이 주장하였듯이, 다큐드 라마의 허구성이 역사의 권위를 무너뜨리거나 또는 대중 을 기만하는 것과 같은 큰 문제점으로 이어지고 확산되는 경우는 드물고 또 일어날 가능성이 별로 없다. 청중들의 대부분은 무엇이 사실이고 또 무엇이 허구인지 잘 분별할 줄 안다. 또한 다큐드라마의 어느 지점에서 사실의 증명 이 필요하고 또 허구의 창조가 요긴한지에 대해서도 잘 알고 있다는 것이다. ${ }^{13)}$

다큐드라마의 역사적 유의미성을 타진해보는 유익한 방식은 그것을 실제 존재했던 '있는 그대로'의 과거에 대 한 ‘변형', '손질', '왜곡' 등으로 재단하기보다는, 다큐드라 마가 오늘을 사는 우리에게 어떠한 의미와 가치를 제공하 고 또 매개할 수 있는지에 대한 '가능성'의 관점에서 재고 하는 것이다. 과거에 대한 우리의 '앎'은 옳을 수도 있고 틀릴 수도 있다. 또한 모두 같을 수도 있고 또 서로 다를 수도 있다. 그렇다고 해서 과거에 대한 이 '앎'의 차이와 다름이 꼭 현재의 혼란을 의미하는 것은 아니다. 이렇듯, 과거에 대한 인간의 인식론적 한계를 늘 체감하기에 우리 는 그 '옳음'과 '그름', 그리고 '같음'과 '다름'의 여부와 경 중 등을 늘 사유하고 숙고하며 때로는 협상하고 논쟁하 며 산다. 특히 특정한 과거에 대한 다양한 '앎'이 필요하 고 또 중요할 때, 다큐드라마가 우리에게 값지고 소중한 많은 것들을 제공하고 또 매개하는 가능성을 발산할 수 있다.

이러한 관점과 맥락에서, 필자들은 다큐드라마를 과거 를 재현하는 하나의 '모드(mode)'로 접근하여 이해하는 것을 강조한다. Lipkin(2011)이 주장하였듯이, 다큐드 라마는 전달하고자 하는 이야기 내용들의 한 유형과 같은 '장르(genre)'가 아니라, 과거에 대한 특정한 주장을 이야 기 형식의 재현을 통해 제공하는 '모드(mode)'이다. '모 드'가 함축하는 것은 재현의 '내용'이 아니라 '표현 수단'이 다. 예컨대, 뮤지컬을 대사와 노래로 구성된 재현의 '모드'

13) Rosenthal(1999)은 세 가지 요인이 결합되어 발생해야만, 사 실과 허구의 조합이 사회적으로 위험한 결과를 초래할 수 있음 을 인정할 수 있다고 논하고 있다. 첫째, 청중들이 완전히 혹은 거의 전적으로 허구를 사실로 오인하는 경우, 둘째, 왜곡되고 허구적인 요소와 요인이 실제 이야기에 현실적 영향을 미치는 경우, 끝으로 표현된 주제가 지속적으로 사회구성원의 특정한 정치/역사/사회/경제/문화적 행동 및 태도에 지대하면서도 중 요한 영향을 미치는 경우이다.
로 인식하듯이, 다큐드라마 역시 그 자체로 독특한 재현 의 표현수단을 가진 '모드'로 식별할 수 있다는 것이다. 재 현의 '모드'로서 다큐드라마는 과거에 실존했던 인물과 사 건이라는 주제와 내용 그리고 고전적 할리우드의 이야기 구조와 전략의 조합으로 작동되는 하나의 미디엄이다.

Lipkin(2011)은 한 걸음 더 나아가 이러한 다큐드라 마의 '모드'를 리얼리티 (reality) TV 프로그램과 비교하 여 논의한다. 그가 보기에, 두 모드의 유사성을 관통하는 것은 '공연(performance)'의 메타포이다. 리얼리티 TV 프로그램은 출연자들이 그들의 일상을 드러내고 보여주 며 재연하는 현실에 대한 '공연'으로 이해할 수 있다. 비 슷한 방식으로, 그는 다큐드라마를 실존했던 인물들의 행 적과 사건들을 재현하는 과거에 대한 '공연'으로 이론화 한다. 그리고 두 '모드' 사이에 존재하는 차이점을 강조하 는데, 그것은 주체들이 '공연'하고자 하는 '주제'와 '내용 '에 대한 합목적성의 유무이다. 리얼리티 TV가 특정한 구 심적 주제와 내용 없이 너무 많은 것들을 산발적으로 표 현하고 연기하는 '공연'이라면, 다큐드라마는 과거에 대 한 특정한 '주장'을 전달하고 설득하기 위해 펼치고 수행 하는 '공연'이라는 것이다. ${ }^{14)}$ 다시 말해, 다큐드라마가 보 여주는 것은 과거에 실존했던 특정 인물과 사건 그 자체 에 대한 '있는 그대로'의 객관적 모습이 아니다. 과거 그 자 체를 복사하여 보여주는 블랙박스와 같은 거울이라기보 다는, 과거에 대한 하나의 시각과 관점을 이야기로 재현하 고 공연하는 것이 다큐드라마가 '모드'로서 가지는 핵심적 인 본질이다.

이 지점에서, Lipkin(2011)은 '공연'의 메타포를 '기억' 이라는 또 다른 키워드와 연관시킨다. 그에 따르면, '공연' 을 한다는 것은 특정한 행위를 역할 행동의 의미를 고려 하면서 무대와 환경 그리고 조건 속에서 전개하는 것이 다. 그리고 이러한 과정은 우리가 과거에 대한 '기억'을 만 들고 구성하는 과정과 매우 흡사하다는 점을 강조한다. 예컨대, 카메라의 작동과 기법으로 창출되는 이미지와 영 상은 과거를 기억하는 기술이자 기법인 셈이다. 그리고 그것들을 통해 우리는 과거를 구성하고, 또 구성한 과거

14) 다큐드라마의 '모드'를 '공연'의 메타포로 이해하는 접근은 Lipkin (2011)에 의해서만 주장된 것은 아니다. Paget $(2002,2007)$ 는 과거를 재현하는 다큐드라마의 핵심적 특징 '사실을 가지고(혹 은 그것을 통해) 행하는 연기(acting with facts)'에 있음을 피 력한 바 있고, Edgar (1999) 역시 다큐드라마 작가들의 입장과 관점에서 다큐드라마는 마치 '사실의 극장(theater with facts)' 과 같음을 주장하였다 
를 현재에 위치시키며 의미를 만들고 또 해석한다. 여기 에서 '기억'이라는 것은 과거를 있는 그대로 복사하여 보 존하는 것을 의미하는 것이 아니다. 과거에 일어났던 구체 적인 행위와 행동을 과거 속 조건과 환경 그리고 맥락 등 과의 관계 속에서 균형감 있게 해석하고 판단하여 주장하 는 것 또한 우리가 살아가면서 과거를 '기억'하는 중요한 방식이다. 즉, 다큐드라마는 과거에 실존했던 인물과 사 건에 대한 하나의 기억을 주장하는 재현의 모드인 것이다.

이하에서는, 과거를 재연하고 재현하는 '공연'과도 같 은 다큐드라마가 '기억'이라는 실제와 어떠한 관련이 있 는지, 그리고 그 관련성 속에서 어떠한 역사적 유의미성 을 사유해볼 수 있는지 등에 대해 서술한다.

\section{문화적 기억을 생성, 매개하는 다큐드라마}

다큐드라마는 실존했던 인물 혹은 실제 일어난 사건 등을 이야기의 형식으로 구성하여 재연(공연)하는 것을 통해 과거에 대한 하나의 기억을 주장하고 설득하는 역사 적 재현의 방식이다. 이 점을 받아들이고 또 고려한다면, 이제 우리는 다큐드라마 속 이야기가 실제 일어난 일인 지를 의심하고 확인하는 접근에서 벗어나, 과거를 '기억' 하는 것과 같은 이 이야기 속의 사람과 사건이 지금 우리 에게 무슨 말을 건네고 있으며, 나아가 그것은 우리가 사 는 사회와 세상 속에서 어떠한 영향을 발휘하고 매개하 는지를 질문해보는 태도를 취할 필요가 있다. 다시 말해, 과거의 특정한 인물과 사건에 대한 하나의 '기억'을 재연 하고 공연하는 다큐드라마들의 역사적 중요성과 유의미 성은 무엇인가? 그것들은 어떠한 문화적 메시지를 담고 있으며 또 우리의 사회·문화 속에서 어떠한 역할과 기능 을 수행하고 있는가?

다큐드라마가 과거를 다루고 이야기하며 소통하는 대 중문화의 지배적 아이콘으로 부각된 배경과 맥락은 문 화적 현상으로서의 '집합적 기억 (collective memory)'이 역사적, 정치적, 사회·문화적 이슈로 등장하게 된 흐름과 궤를 같이하고 있다. 무엇보다, 다큐드라마를 둘러싼 '역 사적' 담론의 이슈와 논쟁이 점화되기 시작한 1990년대 는 북미와 서유럽의 사회·문화계가 소위 '정체성(identity)'의 화두로 '문화 전쟁 (culture war)'이 첨예하게 달 아올랐던 시기이다. '개인적인 것이 곧 정치적인 것'이라는 구호를 필두로 '차이의 정치학(politics of difference)'을 강조하는 목소리들이 과거를 이해하고 소유하며 소통하
는 실제에도 스며들었는데, 문화적 삶과 관련해서는 '기 억'과 관련된 문제의식과 질문들이 많은 논쟁과 토론을 양산했다. 대중문화계 역시 이러한 정체성의 이슈가 경합 되고 투쟁되는 활발한 시공간이었는데, 특히 다큐드라마 를 포함하여 과거에 대해 이야기를 하는 대중 영화들이 야말로 기억을 생성하고 매개하며 소통하는 미디엄이자 동시에 문화적 정체성의 전쟁이 펼쳐지는 하나의 중요한 플랫폼으로 부상한 것이다.

대중문화와 기억의 접점을 바라보는 학술계의 시각, 특히 영화, 다큐멘터리, 다큐드라마 등의 영상미디어들 이 소환해내는 '기억'들에 대한 해석은 주로 '(공적)역사' 와 대비되는 '대항적인 것'으로 특징짓는 것이 지배적이 었다. Grainge(2003)가 주장하듯이, 과거에 대한 기억을 재현하고 소환하는 영화적 텍스트들은 기존의 역사와 구 별되는 차이의 정치학과 저항의 목소리를 드러내고 또 공 론화하는데 기여한다는 것이다. 결국, 과거에 대한 재현 의 역사물로서 영화적 텍스트들은 '대중/공공역사(public/ popular history)'의 한 부분으로 창출되고 나아가 '공식 역사(official history)'의 긴장을 형성하며 대중들에게 다 가가는 것이다.

특히, 다큐드라마들의 집합적 출현과 확산 그리고 그 러한 현상의 역사적 의미와 유용성을 해석하고 읽어내는 틀로서, 필자들은 Sturken(1997)이 제시한 '문화적 기억 (cultural memory)'에 주목한다. 그녀에 의하면,

'문화적 기억'이란 복잡한 정치적 의미들과 이해관계들이 얽 혀 있는 하나의 과정이다. 그것은 문화를 정의하면서 특징 짓기도 하고, 동시에 문화적 구분과 충돌이 진행되고 드러나 는 통로이기도 하다. 기억을 '문화적인 것'으로 정의하는 접 근은 기억이 의미하는 것에 대한 논쟁 속으로 들어가는 것이 다. 그 속에서 개인의 존재적 의미는 상실되는 것이 아니라, 오히려 서로 다른 개인들과의 상호작용을 통해 의미를 생산 하고 창출하는데 관여한다. 따라서 '문화적 기억'은 과거에 대한 서로 다른 이야기들이 역사의 한 부분을 차지하기 위해 서로 경합하고 투쟁하는 하나의 '장(field)'이라 할 수 있다 (Sturken, 1997)

이상의 인용문에서, Sturken(1997)이 이야기하는 '문화' 란, 소위 Stuart Hall 식의 문화론, 즉 다양한 이해관계의 입장과 권력관계의 주체들이 상호작용하면서 경합하고 투쟁하는 의미/상징 생산의 '싸움터(contested terrain)' 로서의 문화이다. 따라서 '문화적 기억'은 기억을 '문화적 현상'으로 인식하고 탐구하는 '문화연구'적 접근과 발상이 
라 할 수 있다.

'문화적 기억'을 생산하고 매개하는 원천이자 수단인 다 큐드라마들이 가장 '집중적으로' 그리고 '진지하게' 천착한 주제가 바로 '미국적 정체성 (American Identity)'이라는 아이디어이다. 미국 사회의 문화적 영역 전반에서, '미국 적' 과거를 둘러싼 기억의 경합과 투쟁은 크게 두 진영으 로 구축되었다고 할 수 있다. 한 쪽은 '미국'이라는 국가/ 공동체를 전통적으로 상상하고 이야기해온 방식과 스타 일을 한층 더 강화하는데 주력하였다. 다른 한쪽은 그러 한 '지배적' 내러티브의 획일성, 즉 미국적 과거의 단일성 (singularity)에 도전하고 '차이'와 '다원성'의 목소리를 강 조하면서 문화전쟁에 합류하였다. 1980년대 말부터 1990 년대에 제작/생산된 많은 다큐드라마들이 이 후자의 진 영과 관련되어 있다. 이들은 주로 인종, 정치적 암살, 베 트남 전쟁과 같은 주제와 사건들에 대한 기억과 망각, 그 리고 그 둘 사이의 관계에 작동하는 정치적 행간을 환기 하는데 초점을 맞추고 있다.15) 이렇듯, 다큐드라마는 사 회 속에서 문화적 기억을 생성하고 매개하는 플랫폼이자 미디엄으로서 역할하고 기능하는 역사화의 주체로 자리 하고 있다.

지금까지, 다큐드라마의 개념과 정의 그리고 그 형식 과 내용을 아우르는 성격, 아울러 그것은 왜 그리고 어떻 게 '역사적으로' 유의미한 것인지 등을 서술하였다. 이러 한 다큐드라마 연구의 지형과 담론에 대한 정보를 바탕으 로, 다음 장에서는 스포츠다큐드라마에 대해 어떠한 시각 과 관점으로 접근할 필요가 있는지, 아울러 그러한 접근 의 학술적 태도가 스포츠역사학의 발전과 확장에 어떻게 기여할 수 있는지 등을 논의한다.

\section{'스포츠다큐드라마' 연구의 스포츠문화(史)적 가치와 의의}

이 장에서는, 앞 절에서 서술한 다큐드라마 연구의 지 형을 토대로 스포츠다큐드라마 연구의 역사적 의의와 유 용성을 크게 두 가지로 구분하여 논의한다.

첫째, 스포츠다큐드라마는 대중문화의 세계 속에서 새

15) «Born on the Fourth of July(1989)», «Dances with Wolves(1990)》, 《JFK(1991)》, «Malcolm X(1992)》, 《Forrest Gump(1994)》, 《Nixon(1995)》, «Saving Private Ryan(1998)》 등이 대표적이다.
롭게 생성되거나 또는 이전 혹은 다른 기억들과 특정한 관계를 맺으며 기억 문화의 생태계 속에 존재하여 기능하 는 하나의 '스포츠 기억하기'로 인식할 필요가 있다. 사 실, '기억'이라는 학술적 주제 혹은 아이디어가 한국의 체 육-스포츠역사학계서 전혀 논의되지 않았거나 또는 탐구 되지 않고 있는 것은 아니다. 예컨대, 우수한 성적을 올린 운동선수들을 대상으로 그들의 기억을 기록하고 역사화 하는 많은 작업들이 꾸준히 진행되고 있다. 다시 말해, 이 러한 연구들은 과거의 스포츠를 탐구하기 위한 수단으로 기억을 활용하고 있다는 점에서 충분히 의미 있고 또 가 치가 있는 스포츠역사연구들이다.

이 지점에서, 생각해볼 점은 기억을 활용하는 목적 역 시 다양할 수 있다는 것이다. 간단히 말해, 기억은 과거를 투명하게 비추어주는 거울이기도 하고, 동시에 과거를 특 정하게 재구성하는 것이기도 하다. 그래서 한편으로 우 리는 과거에 일어난 사건이나 사실에 대해 있는 그대로 의 진실 혹은 정보를 알아보기 위해 기억을 활용할 수 있 다. 또 다른 한편으로, 우리는 그 사건이나 사실에 대해 사 람들이 어떻게 의미부여 하는지, 그리고 그들이 느꼈던 감 정, 태도, 정서, 의미 등은 어떠한지에 대해 공감하기 위해 기억을 활용할 수도 있는 것이다. 특히, 필자들은 바로 이 후자의 쟁점이 스포츠다큐드라마 연구가 스포츠역사학 의 비전과 가치를 확장하는데 기여할 수 있는 핵심 가치 라고 믿는다.

그렇다면, 한국의 역사적 맥락과 스포츠 현실 속에서, 스포츠다큐드라마는 기억과 관련하여 어떠한 역사적 의 미와 유용성을 생성, 매개, 소통하는데 기여할 수 있는가? 앞 장에서 언급하였듯이, 미국의 경우, 할리우드가 '문화 전쟁'의 대중 문화적 시공간으로 등장하여 부각되기 시작 한 것은 1980년대 후반부터 1990년대 초반에 이르는 기 간이다. 이 현상을 촉발한 다양한 요인들 중의 하나는, 과 거에 대한 우리의 현재적 앎을 이전과는 다른 방식으로 이해하고 성찰하기 시작한 일종의 인식론적 전환이 자리 하고 있다. 예컨대, 미국적 정체성과 미국적 과거라는 것 에 대한 만장일치의 기억과 역사는 존재하지 않을 수 있 다는 역사의식이 대표적이다. 비단, 미국이라는 국가가 무엇인지를 상상하는 것뿐만 아니라, 과거에 대한 무수히 많은 것들이 이제는 '누구에 의해 누구를 위해 기억하는 것인가라는 질문으로부터 자유로울 수 없게 된 것이다.

필자들의 주장은, 이러한 기억 문화의 정치성을 한국 사회 속에서 스포츠와 연관지어 생각해볼 필요가 있고 또 
그것을 탐구해볼 가치가 있다는 것이다. 누구를 위한 과 거이고 누가 무엇을 위해 기억하는 것인가의 이슈와 쟁점 은 한국의 영화계에도 일찍 스며들어 꿈틀거리고 있다. 예컨대, 친일, 남북 관계, 군사독재, 민주화 투쟁 등과 같 은 주제와 이슈들이 스크린을 통해 과거에 대한 우리의 앎 또는 역사와 관련된 기억들의 생성, 강화, 경합, 협상, 저항, 투쟁 등과 연결되고 있다.

이에, 우리는 다음과 같은 질문들을 제기할 수 있다. 과거의 스포츠를 재현하는 다큐드라마들은 한국 사회 속 에서 어떠한 기억 문화의 정치적 지형을 형성하고 또 그 속에서 어떠한 기능, 역할하고 있는가? '생산-전달-소비/ 수용'되는 과정을 통해 텍스트 밖 사회 속으로 나아가는 한 편의 스포츠다큐드라마는 어떠한 대중적 기억과 연관 되어 의미화되는가? 스포츠는 특정한 지배적 기억을 재 생산하고 재 강화하는 주제이고 또 스포츠다큐드라마는 그러한 기능과 역할을 하는 대중(문화)적 미디엄, 모드, 장르인 것인가? 아니면, 이른바 대항적 기억을 생산하고 매개하는 주제이자 모드 혹은 장르인 것인가? 과거의 스 포츠는 한국 사회 속에서 누구에 의해 누구를 위한 것으 로 기억되고 있는가?

과거의 스포츠만을 탐구하고 그것에 대해 학술적으로 이야기하는 것만이 체육·스포츠역사학자들이 지식생산자 로서 추구해야 하는 비전은 아닐 것이다. 아니, 그것을 기 반으로 하되, 우리는 과거와 함께 현재도, 역사 뿐 아니라 기억까지도 아우르며 더 크고 넓게 나아갈 필요가 있다. 스포츠다큐드라마를 중심으로 빚어지는 정치성의 지형이 바로 이러한 비전의 확장을 모색할 수 있는 유용하면서도 유익한 분야인 것이다.

둘째, 스포츠역사학자들은 스포츠다큐드라마가 내장하 여 전송하는 허구성의 이슈와 문제에 대해서도 '특별한' 학술적 관심과 문제의식을 가지고 접근, 탐구할 필요가 있다. 본론에서 서술하였듯이, 스포츠역사학자들은 주로 '진실성' 혹은 '사실성'에 기초하여 스포츠다큐드라마를 실 제 과거와 비교, 대조하면서 그 허구성을 밝히고 드러내 는데 초점을 두어 왔다. Schultz(2014)가 인용하여 비판 적으로 설명한 바 있듯이, Thomas Doherty라는 학자는 역사적 영화를 대하는 많은 역사학자들이 마치 사소한 것 들을 자주 들추어내는 사람들처럼 과거에 대한 진실과 관 련된 작은 것들을 지적하고 교정하고 또 바로잡아주는 것 에 기빼한다고 비꼬기도 하였다.

물론, 스포츠역사학자들이 스포츠다큐드라마가 드러내
는 과거에 대한 객관적 오류, 사실과 다른 허구적 요소, 그리고 편향된 왜곡 등을 바로잡는 역할을 하는 것은 중 요하고 또 필요한 일이다. 그러나 꼭 그것만이 스포츠역 사학자들이 스포츠다큐드라마에 대해 접근하여 학술적 으로 탐구하는 유일한 방식은 아니다. 북미스포츠역사학 회의 임원진이자 스포츠문화연구학자이기도 한 Schultz (2014)는 할리우드에서 생산되고 있는 스포츠다큐드라 마의 허구성을 조금 다른 관점에서 문제화하여 연구하는 대표적 학자인데, 그녀의 작업이 한국의 체육·스포츠역사 학자들에게도 매우 유의미한 시사점을 제공한다고 판단 되어 잠시 소개하고자 한다.

$\operatorname{Schultz}(2014)$ 는 과거에 실제 일어난 스포츠 이야기 를 소재로 인종적 통합의 이슈와 쟁점을 주제로 다루는 3편의 스포츠영화, 《Remeber Titan》(2000), 《Glory Road》 (2006), 《The Express》 (2008)를 대상으로 하 여 과거에 대한 역사적 '진실'의 문제를 논의한다. 그녀에 의하면, 3편의 스포츠다큐드라마들은 과거에 일어난 실 제 스포츠 사건과 다른 사실적 오류와 비정확성을 드러내 고 있다. 그것들은 주로 네 가지 유형인데, 연대기와 같은 시간적 순서의 오류, 실제 인물에 대한 왜곡, 과거의 실제 인물들이 나눈 대화의 조작, 그리고 실제 인물들을 둘러 싼 사건의 날조와 같은 패턴을 띠고 있다는 것이다. 이 지 점에서, Schultz(2014)는 (스포츠)역사학자들이 대응하 는 지배적 방식, 즉 다큐드라마의 허구성이 제기하고 양 산하는 비역사성의 심각성을 지적하고 비판하는 논지로 나아가지 않는다. 그렇다고 해서, 사실적 오류와 비정확 성이 아주 작고 미미한 부분에 불과하다는 점을 강조하며 다큐드라마의 허구성을 옹호하는 것도 아니다.

Schultz(2014)가 주장하는 바는, 3편의 스포츠다큐드 라마에 드러나는 사실적 오류와 비정확성이 비교적 작은 부분들인 것은 맞지만, 그것들이 실제 과거의 스포츠 사 건과 다르기 때문에 의미가 없는 것이 아니라, 오히려 특 정한 역사를 만들어내고 있기 때문에 매우 의미가 크다 는 것이다. 다시 말해, 영화 속 오류와 실수 혹은 왜곡들 은 영화가 제작된 당시의 인종적 담론으로부터 파생된 특 정한 정치적, 이데올로기적 역할을 수행하는데, 그것은 바 로 인종주의를 일종의 지나간 과거로 채색하고 또 스포츠 관련 인물들을 인종 문제에 있어 영웅적 수준의 책무를 가진 주체로 자연스레 포장한다는 것이다. 즉, 그녀의 작 업은 과거의 실제 스포츠 사건과 인물에 대해 스포츠다 큐드라마가 허구성을 덧칠하는 양상과 방식에 담겨 있는 
정치성의 행간을 비판적 안목과 통찰로 꼬집고 있는 셈 이다.

결국, Schultz(2014)의 요지는, 주류-전문 스포츠역사 학자들이 과거의 실제 스포츠 사건과 '다른' 사실적 오류 와 왜곡 등에 집착한 나머지, 스포츠다큐드라마가 표상하 고 재현하는 보다 더 큰 차원의 '상징적 진실' symbolic truth)을 간파하고 해석하는 데 실패하고 있다는 점이다. Toplin(2002)이 재치 있게 묘사했듯이, 작은 거짓말들에 집착한 채, 거대한 진실을 인식하지 못하는 것이다. 역사 학자들은 스포츠다큐드라마의 내러티브 속에 과거의 실 제 스포츠 사건과 다른 작은 거짓말들이 들어 있음을 이 야기함과 동시에, 바로 그 (작은) 거짓말들이 과거와 현 재 사이의 관계에서 어떠한 의미를 띠고 소통되는지에 대 해서도 개입하여 논평할 수 있어야 한다. 이것이 바로 무 수히 많은 미디엄들을 매개로 '스포츠 역사하기'의 민주화 가 펼쳐지고 있는 대중/공공역사학의 시대에, 체육·스포 츠역사학자들이 짊어져야 할 또 하나의 책무이자, 체육. 스포츠역사학의 비전을 확장하는 유의미한 방식이다. 이 세상에 인간이 만들어내는 모든 것들은 그것들 나름의 의 미가 다 있다.

\section{참고문헌}

Andrea, A. (1991). On Public History. Historian, 53, 381-386.

Booth, D. (2005). Evidence Revisited: Interpreting Historical Materials in Sport History, Rethinking History, 9(4), 459-483.

Burke, P. (2002). Western Historical Thinking in a Global Perspective - 10 Theses. In J. Rusen (Eds.), Western Historical Thinking: An Intercultural Debate (pp. 15-30). New York; Oxford: Berghahn Books.

Caughie, J. (1980). Progressive Television and Documentary Drama. Screen, 21(3), 9-35.

Champion, J. (2003). Seeing the Past: Simon Schama's 'A History of Britain' and Public History. History Workshop Journal, 56, 153-174.

Chapman, J., Glancy, M., \& Harper, S. (2007), Introduction. In J. Champman, M. Glancy, \& S. Harper (ed.) The New Film History: Sources, Methods, Approaches (pp. 1-10). Basingstoke; New York: Palgrave Macmillan.

Corner, J. (1999). British TV Dramadocumentary: Origins and Developments. In A. Rosenthal (Eds.), Why Docudrama?:
Fact-fiction on Film and TV (pp. 35-46). Carbondale, Ill: Southern Illinois University Press.

Custen, G. (1992). Bio/Pics. New Brunswick, New Jersey: Rutgers University Press.

Custen, G. (1999). Clio in Hollywood. In A. Rosenthal (Eds.), Why Docudrama?: Fact-fiction on Film and TV (pp. 19-34). Carbondale, Ill : Southern Illinois University Press.

De Groot, J. (2006). Empathy and Enfranchisement: Popular Histories. Rethinking History, 10(3), 391-413.

Doherty, T. (2002). Film and History, Foxes and Hedgehogs. $O A H$ Magazine of History, 16(4), 13-15.

Edgar, D. (1999). Theater of Fact: A Dramatist's Viewpoint. In A. Rosenthal (Eds.), Why Docudrama?: Fact-fiction on Film and TV (pp. 174-187). Carbondale, Ill : Southern Illinois University Press.

Feuer, J. (1995). Seeing through the Eighties: Television and Reaganism, Durham: Duke University Press.

Fraser, G. (1999). Hollywood and World History. In A. Rosenthal (Eds.), Why Docudrama?: Fact-fiction on Film and TV. (pp. 12-18). Carbondale, Ill : Southern Illinois University Press.

Gerlach, L. (1996). The Final Three Innings. Journal of Sport History, 23(1), 72-77.

Grafton, A. (1997). The Footnote: A Curious History. Cambridge, Mass.: Harvard University Press.

Grainge, P. (2003). Memory and Popular Film. Manchester: Manchester University Press.

Ha, W. Y. \& Chung, H. K. (2010). The Factional Analysis of Sport Movie through Oral History: Focus on 'Forever the Moment'. The Korean Journal of Physical Education, 49(6), 1-12.

Harlan, D. (2003). Ken Burns and the Coming Crisis of Academic History. Rethinking History: The Journal of Theory and Practice, 7(2), 169-192.

Harlan, D. (2007). Historical Fiction and Academic History. In K. Jenkins, S. Morgan, \& A. Munslow (ed.), Manifestos for History (pp. 108-130). London; New York: Routledge.

Hoffer, T. \& Nelson, R. (1978). Docudrama on American TV. Journal of the University Film Association, 30(2), 21-27.

Huh, J. S. (2014). A Study on Film ${ }^{『}$ Olympia $₫$ as Historical Reference for Research on Sohn Kee-Chung. The Korean Journal of History for Physical Education, Sport, and Dance, 19(1), 53-68.

Hyung, D. (2016). Between Documentary and Fiction, and These Combination: Documentary Fiction or Fictional Documentary? Film Studies, 67, 185-213.

Jay, M. (2002). That Visual Turn: The Advent of Visual Culture. 
Journal of Visual Culture, 1(1), 87-92.

Jordanova, L. (2000). History in Practice. London: Arnold; New York: Oxford University Press.

Kim, K. D. (2008). Visual History: Enlargement of the Role of History and Its New Responsibilities. The Korean Historical Review, 200, 99-130.

Kim, J. \& Ha, W. (2015). The Factional Analysis of Sport Movie 'Perfect Game.' The Korean Journal of History for Physical Education, Sport, and Dance, 20(1), 13-27.

Kim, Y. S. \& Kim, J. Y. (2014). The History of Taekwondo Movies Characteristics in Korea. The Korean Journal of Physical Education, 53(5), 1-9.

Kim, B. \& Seo, J. C. (2012). Douglas Booth's Critical Perspectives on Modern Sport Historiography and Its Implications for Korean Sport Historiography. The Korean Journal of Physical Education, 51(5), 1-15.

Lipkin, S. (2002). Real Emotional Logic: Film and Television Docudrama as Persuasive Practice. Carbondale Ill.: Southern Illinois University Press.

Lipkin, S. (2011). Docudrama Performs the Past: Arenas of Argument in Films Based on True Stories. Newcastle upon Tyne: Cambridge Scholars Publishing.

Mirzoeff, N. (1999). An Introduction to Visual Culture. New York: Routledge

Mitchell, W. J. T. (2002). Showing Seeing: A Critique of Visual Culture. Journal of Visual Culture, 1(2), 165-181.

Nathan, D. A. (2014). Baseball As the National Pastime: A Fiction Whose Time is Past. The International Journal of the History of Sport, 31(1-2), 91-108.

Paget, D. (1990). True Stories: Documentary Drama on Radio, Screen and Stage. Manchester: University Press.

Paget, D. (2002). Acting a Part: Performing Docudrama, Media International Australia, 104(1), 30-41.

Paget, D. (2004). Codes and Conventions of Dramadoc and Docudrama. In R. C. Allen \& A. Hill (Eds.), The Television Studies Reader (pp. 196-208). London; New York: Routledge.

Paget, D. (2007). Acting with Facts: Actors Performing the Real in British Theatre and Television since 1990. Studies in Documentary Film, 1(2), 165-176.

Pope, S. W. (1996). Roundtable: Ken Burns' Baseball, Introductory Comment. Journal of Sport History, 23(1), 61-62.

Phillips, M. G. (2008). Public History and Sport History: Evaluating Commissioned Histories and Historical Documentaries. Journal of Sport History, 35(3), 393-410.

Phillips, M. G., O’Neill, M. E. \& Osmond, G. (2007). Broaden- ing Horizons in Sport History: Films, Photographs, and Monuments. Journal of Sport History, 34(2), 271-293.

Rhodes, G. \& Springer, J. (2006). Docufictions: Essays on the Intersection of Documentary and Fictional Filmmaking. Jefferson NC: McFarland.

Riess, S. (1996). The Early Innings. Journal of Sport History, 23(1), 63-68.

Rosenstone, R. A. (1988). History in Images/History in Words: Reflections on the Possibility of Really Putting History onto Film. The American Historical Review, 93(5), 1173-1185.

Rosenstone, R. A. (1992). JFK: Historical Fact/Historical Film. The American Historical Review, 97(2), 506-511.

Rosenstone, R. A. (1995). Visions of the Past: the Challenge of Film to Our Idea of History. Cambridge, Mass.: Harvard University Press.

Rosenthal, A. (1999). Introduction. In A. Rosenthal (Eds.), Why Docudrama?: Fact-fiction on Film and TV. (pp. xiii-xxi). Carbondale, Ill : Southern Illinois University Press.

Schultz, J. (2014). The Truth about Historical Sport Films. Journal of Sport History, 41(1), 29-45.

Seo, J. C. \& Kim, B. (2015). A Historiographical Review on Public/Popular History of Sport and Its Implication for Korean Sport Historiography. Korean Journal of Sport Science, 26(2), 342-355.

Sturken, M. (1997). Tangled Memories: The Vietnam War, the AIDS Epidemic, and the Politics of Remembering. Berkeley: University of California Press.

Thelen, D. (1994). The Movie Maker as Historian: Conservations with Ken Burns. The Journal of American History, 81(3), 1031-1050.

Toplin, R. B. (2002). Reel History: In Defense of Hollywood. Lawrence: University Press of Kansas.

Toplin, R. B. (2009). History by Hollywood. Urbana: University of Illinois Press.

Tygiel, J. (1996). Ken Burns Meets Jackie Robinson. Journal of Sport History, 23(1), 69-71.

Walkowitz, D. (1985). Visual History: The Craft of the HistorianFilmmaker. The Public Historian, 7(1), 53-64.

White, H. (1988). Historiography and Historiophoty. The American Historical Review, 93(5), 1193-1199.

Wildt, M., \& Selwyn, P. (1996). The Invented and the Real: Historiographical Notes on Schindler's List. History Workshop Journal, 41, 240-249.

Woodhead, L. (1981). The Guardian Lecture: Dramatised Documentary. BFI, 19 May. 


\section{스포츠다큐드라마 연구를 통한 체육·스포츠역사학의 확장}

\section{서재철(서울대학교), 김방출(서울교육대학교)}

[목적〕 이 연구는 사실과 허구가 조합하여 공존하는 '다큐드라마'라는 특정한 장르의 출현에 주목하고, 과거 의 스포츠를 다루고 재현하는 스포츠다큐드라마에 대한 학술적 관심과 탐구가 체육·스포츠역사학의 확장과 책 무라는 관점에서 어떠한 가치와 유의미성을 제공하고 마련하는지를 살펴보는 것이다. 〔방법) 이 연구는 문헌 연구로서 크게 세 가지 분야의 문헌들에 대한 비판적, 해석적 리뷰를 실시한다. 첫째, 역사적 (스포츠)영화의 역사성 혹은 비역사성을 논의, 주장, 제기, 검토한 (스포츠)역사학자들의 저서, 논문, 논평, 에세이들, 둘째, '다 큐드라마'라는 장르를 구심점으로 형성되어 있는 소위 '다큐드라마 연구'와 관련된 문헌들, 셋째, 영상역사 혹 은 영화적 역사하기의 가능성과 잠재성을 주목하고 새로운 시각문화 중심의 역사학을 지향하고 탐색, 논의하 는 문헌들이다. 〔결과〕 문헌 검토와 리뷰의 과정을 통해, 이 연구의 결과를 크게 세 부분으로 구성하여 제시한 다. 첫째, 체육·스포츠역사학자들이 과거의 스포츠를 다루거나 재현하는 대중(문화)적 영상물에 대해 어떠한 지배적 관점을 가지고 비판적으로 지적하고 또 문제화하고 있는지를 북미와 한국의 사례로 구별하여 소개한 다. 둘째, 역사적 영화가 생성, 매개, 제공하는 새로운 내용과 성격의 역사적 유의미성을 탐색, 논의한 연구들 의 핵심 쟁점을 요약, 정리한다. 셋째, 다큐드라마 연구의 지형과 담론을 크게 세 가지 항목, 개념적 정의, 과거 를 재현하는 모드로서의 성격, 문화적 기억과의 연관성을 중심으로 개괄하여 소개한다. 〔결론) 이상의 결과를 토대로, 스포츠다큐드라마에 대한 학술적 관심과 탐구가 체육-스포츠역사학의 확장과 책무라는 비전과 명제에 어떻게 기여할 수 있는지에 대한 가치와 유의미성을 제안하고 주장한다.

주요어: 다큐드라마, 재현의 모드, 문화적 기억, 상징적 진실, 스포츠영화 